\title{
Backscatter calibration of high-frequency multibeam echosounder using a reference single-beam system, on natural seafloor
}

\author{
Eleftherakis Dimitrios ${ }^{1}$, Berger Laurent ${ }^{1}$, Le Bouffant Naig ${ }^{1}$, Pacault Anne ${ }^{1}$, Augustin Jean-Marie ${ }^{1}$, \\ Lurton Xavier ${ }^{1}$,
}

${ }^{1}$ Inst Francais Rech Exploitat Mer Ifremer, DFO NSE ASTI, Underwater Acoust Lab, CS 10070, F29280 Plouzane, France.

*Corresponding author : Xavier Lurton, email address : xavier.lurton@ifremer.fr

\begin{abstract}
:
The calibration of multibeam echosounders for backscatter measurements can be conducted efficiently and accurately using data from surveys over a reference natural area, implying appropriate measurements of the local absolute values of backscatter. Such a shallow area (20-m mean depth) has been defined and qualified in the Bay of Brest (France), and chosen as a reference area for multibeam systems operating at 200 and $300 \mathrm{kHz}$. The absolute reflectivity over the area was measured using a calibrated single-beam fishery echosounder (Simrad EK60) tilted at incidence angles varying between $0^{\circ}$ and $60^{\circ}$ with a step of $3^{\circ}$. This reference backscatter level is then compared to the average backscatter values obtained by a multibeam echosounder (here a Kongsberg EM 2040-D) at a close frequency and measured as a function of angle; the difference gives the angular bias applicable to the multibeam system for recorded level calibration. The method is validated by checking the single- and multibeam data obtained on other areas with sediment types different from the reference area.
\end{abstract}

Keywords : Calibration, Seafloor backscatter, Multibeam echosounder, Single-beam echosounder 


\section{Introduction}

Multibeam echosounders (MBES) are used extensively for mapping the seabed since they combine measurement accuracy with operational and economic efficiency. They are well adapted to seafloor-type classification since they jointly record depth data (from the two-way travel times of the signals) and backscatter strength (from the received echo intensities). Both bathymetry features (e.g. depth residuals, see Eleftherakis et al. 2012 and 2014) and backscatter strength (e.g. Canepa and Pouliquen 2005; De Moustier 1986; Fonseca and Mayer 2007; Hellequin et al. 2003; Hughes Clarke 1994; Lamarche et al. 2011; Simons and Snellen 2009) have the potential to be linked to the sediment type covering the seabed. Furthermore, their combination can enhance the discriminatory performance of classification (e.g. Eleftherakis et al. 2012 and 2014). An overview of common bathymetry and backscatter features used in benthic habitat mapping classification can be found in (Diesing et al. 2016). Since the focus of the work presented here is not on classification but on sensor calibration, classification applications will be only briefly contextualized in this first section; an extensive review of the different classification methods can be found e.g. in Brown et al. 2011.

Acoustic sediment classification methods can be divided into empirical (or phenomenological) and model-based (or physical) approaches. The empirical methods use either single (e.g. Amiri-Simkooei et al. 2009) or multiple backscatter features (e.g. Preston 2009, Buscombe et al. 2014), or else combinations of backscatter and bathymetry features (e.g. Eleftherakis et al. 2012, 2014). The outcome is a number of clusters corresponding to separable seafloor types but providing no direct objective information on the sediment nature and characteristics. The connection between classes and sediment properties (most commonly the mean grain size) is only possible through collection of a sufficient quantity of groundtruthing information.

On the other hand the model-based (physical) approaches determine the sediment type by maximising the match between modelled and measured signal features, where sediment types (or indicative parameters of sediment types) are input to the model. The limitation of such methods obviously lies in the relevance of available models: very often they are based on the APL-UW (1994) model which was developed for frequencies between 10 and $100 \mathrm{kHz}$, so that outside this frequency range a model applicability assumption has to be made (e.g. Snellen et al. 2013). This potentially introduces a hindrance for multispectral backscatter strength (BS) classification since most contemporary MBES for coastal waters operate at high frequencies $(200-400 \mathrm{kHz})$.

Whatever the approach (empirical or model-based), consistency of the backscatter levels recorded by MBES is the key point. Indeed the backscatter data should be directly comparable either for one MBES operated at different times over several cruises, or for several different MBES (working at a same frequency). Unfortunately, while accuracy and repeatability of bathymetric measurements are assessed by hydrographic standards (IHO 2008), much less attention has been given to the quality control of MBES backscatter data. Ideally, this consistency is insured by a full absolute calibration of the sonar sensitivity in transmission and reception, giving access to absolute backscatter strength levels.

Recent research has focused on the concept of relative calibration of MBES on reference areas (e.g. Eleftherakis et al. 2014; Weber et al. 2017; Roche et al. 2018) for achieving comparability, and requiring a limited level of calibration. However a more general approach of classification (such as creating a library of backscatter angular response curves for different sediment types at various frequencies) requires absolute MBES calibration. Today, the increasing importance of seabed backscatter in seafloor-mapping (Lurton and Lamarche 2015) raises the issue of calibration of seafloor-survey dedicated sonars used for seafloor backscatter 
intensity measurement in parallel to bathymetry.

The purpose of calibrating BS measurements is to provide the absolute value of the target strength for a unit-surface of the seafloor interface. This implies (1) to operate a sonar system whose response upon target is accurately known (in terms of sensitivity in combined transmission and reception, according to angle and possibly frequency), and (2) to apply correctly to the received backscattered signals accurate compensations for transmission losses, directivity patterns and footprint extent.

The earliest methods proposed in the literature for MBES calibration of echo level reception (see Section 2 for details) were logically inspired from the metrological approach widely used for single-beam echosounders (SBES). Despite the obvious legitimacy of such methods, it is more realistic in many cases to choose a more pragmatic approach, in which the MBES calibration is performed under operational conditions (i.e. on a natural seafloor) by comparison with the data recorded by another reference calibrated sensor. This should make MBES calibration a practically feasible operation for most users, who may find the metrological approach out of their reach - or even materially impossible to conduct in some cases.

In the following, Section 2 presents and discusses shortly four possible approaches for MBES backscatter calibration. Section 3 addresses the methodology for absolute calibration based on the comparison of field data recorded on a same seafloor spot by a calibrated reference SBES and by the MBES to calibrate. The main part of the paper illustrates this concept by one case study: calibration of a Kongsberg EM 2040 MBES using a reference Simrad EK60 on areas located in the Bay of Brest, France, for which the selection of appropriate survey areas for the calibration procedure is presented with the criteria to fulfil for this purpose. Sections 4 and 5 describe the MBES and SBES actual configurations and the data processing techniques applied for this particular case study. The results of the cross-calibration methodology applied on the selected seafloor area are presented and discussed in Section 6; they are completed by comparative measurements on areas with sediment types different than those of the principal area, hence validating the method. Finally, the conclusions and perspectives of the work are summarised in Section 7.

\section{Context and calibration methods}

The echosounder initial calibration should ideally be carried out by its manufacturer, in the best position to control and ensure the equipment characteristics and performances, including the system's acquisition and processing software modules. In-factory calibration operations, checked during the Factory Acceptance Test (FAT), should ensure the system conformity with the nominal characteristics of the model and provide objective deviations from the ideal response. At-sea calibration operations should be conducted, during the Sea Acceptance Tests (SAT) of the sonar in its operational environment. A specific calibration report should be provided to customers, including both the nominal characteristics of the model and the values actually measured in FAT or SAT. Built-in self-test (BIST) capabilities should allow users to verify the calibration quality throughout the system lifecycle. Some manufacturers (Wendelboe et al. 2010, Gutierrez et al. 2016) have started to address these various levels but practical achievement is still at present at an insufficient level.

A second solution, similar to the previous one but possibly conducted independently from the manufacturer, consists in tank measurements of the echosounder considered separately as a transmitter and receiver. The main functional characteristics to be measured are the source 
level on the main axis of the transmitting (Tx) sector, according to the transmitter settings (power, pulse duration, etc.); directivity pattern(s) for the various Tx and Rx sectors, possibly function of frequency; transmitted signal characteristics (pulse duration and shape, distortion rate); receiver sensitivity (including the $\mathrm{Rx}$ antenna and electronics). All these are obtained using conventional laboratory equipment of acoustic metrology (reference hydrophone and projector, and receiving-processing chain), implying a specific measurement environment: a test-tank of a size adapted to the concerned frequencies, with dedicated mechanical devices for high-precision positioning of transducers. Well-adapted to high-frequency MBES, this intank method has been applied to e.g. Kongsberg Mesotech SM2000/SM20 (Cochrane et al. 2003, Perrot et al. 2014), Kongsberg EM3002 (Lanzoni and Weber 2010, 2012), and Kongsberg EM 2040 (Lurton et al. 2013). Considering its heavy constraints in infrastructure and equipment, such an approach remains today reserved to a few specialized laboratories.

A third method is based on the use of an artificial reference target; it is commonly applied to fishery single-beam echosounders (Simmonds and MacLennan 2005; Demer et al. 2015). The principle is to measure directly the combined emission-reception response of the sonar on a point target (practically a dedicated full-metal sphere) with a known frequency-dependent target strength (Gaunaurd and Überall 1983) and accurately positioned in angle thanks to an interferometric capability (split-beam) of the echosounder. This calibration method, simple and robust, has been developed and standardized by the fisheries community which routinely integrate it in the stock assessment surveys. It was naturally extended (Ona et al. 2009) to the calibration of the recent ME 70 and MS-70 MBES structured like a fan of duplicated tilted Rx-Tx single beams with split-beam capability. A similar approach was also recommended for general application to seafloor-mapping MBES (Foote et al. 2005). However, for these systems this calibration method faces several problems: large number (several hundreds) and narrowness (typically about $1^{\circ}$ ) of the Rx beams; difficulty to obtain far-field radiation conditions; lack of accurate localization of the target; insufficient functionalities for processing echo signals from in-water targets. Nevertheless this classical method remains a potential candidate for future MBES systems dedicated to seafloor backscatter measurements with appropriate characteristics (Lurton and Lamarche 2015).

None of the three methods presented above finally provides a practical and widely-acceptable calibration procedure for MBES systems. In this article we propose a cross-calibration method: the MBES data, obtained under operational conditions, are compared to a set of data obtained locally with a calibrated SBES system. The SBES transducer is tilted at various incidence angles in order to obtain a reference angular response of the local seafloor interface. The estimated difference between data from the two sounders provides the MBES measurement biases, to be accounted for in subsequent data processing. The area used for this cross-calibration plays a very important role. It does not need be known in advance; however, to facilitate the processing operations and the interpretation of the data, it should present favourable characteristics (see §3.1). This cross-calibration method offers several advantages: it is straightforward, it calibrates the echosounder as close as possible to its normal operating conditions, and it can be conducted at sea together with routine operations of bathymetry calibration.

In this article we present the case study of a Kongsberg EM 2040 dual-head MBES crosscalibrated with a reference Simrad EK60 SBES. The MBES calibration was performed separately for two frequencies $200 \mathrm{kHz}$ and $300 \mathrm{kHz}$ and compared to two calibrated SBES systems operating at $200 \mathrm{kHz}$ and $333 \mathrm{kHz}$; in principle the calibration frequency of the two systems has to be the same; however the $300 / 333 \mathrm{kHz}$ MBES/SBES cross-calibration was conducted for practical reasons; this frequency-difference impact is discussed in Appendix 1. 


\section{Absolute calibration methodology}

The absolute calibration methodology proposed here includes three phases: a) selection, characterisation and control of a survey area; b) comparative calibration of the MBES vs SBES data on the selected area; and c) verification of the calibration results.

\subsection{Selection, characterization and control of a survey area}

A natural seafloor area appropriate for MBES cross-calibration should fulfil a number of criteria, regarding its topography and reflectivity characteristics. Its dimensions (depth and extent) should be compatible with the MBES capabilities and the calibration survey requirements. Its topography should be flat and horizontal in order to minimize the bottom slope influence. It should show a homogeneous geological facies, with a backscatter angular response as regular and simple as possible.

If the purpose is to settle a permanent reference area, several complementary features must be considered. The area should be easily accessible, little perturbed by traffic and other activities such as trawling or dredging, and ideally it should overlap an area used for bathymetry calibration. The absolute values of backscatter angular response at relevant frequencies should be recorded and checked using a calibrated sonar system, and controlled regularly on dedicated surveys. The temporal stability of its characteristics is paramount in order to ensure a high predictability of its response.

More discussion about the use of natural reference areas for MBES backscatter calibration can be found in (Lurton and Lamarche 2015; Roche et al. 2018; Weber et al. 2017).

\subsection{MBES calibration on a selected area}

The calibration area being selected, MBES calibration operations can be conducted. In case of a permanent reference area, the MBES should ideally follow at least one predetermined line already surveyed during the area characterization campaign. On an opportunistic reference area, SBES and MBES (see Fig.1) should log data on the same line either simultaneously or at least at close moments (to avoid inter-equipment interference). A significant number of pings (several hundreds) should be recorded on each line. The average reflectivity level is calculated for both sounders as a function of the incidence angle. The MBES results are then compared to the SBES ones: the difference between the two datasets defines the MBES response bias, and therefore the compensation to be applied. The operation is valid only for one MBES configuration and it must be repeated as many times as necessary to cover the various possible operational settings. Since the SBES can log data at only one tilt angle per track, recording a complete angular response implies to run the same line an appropriate number of times. 


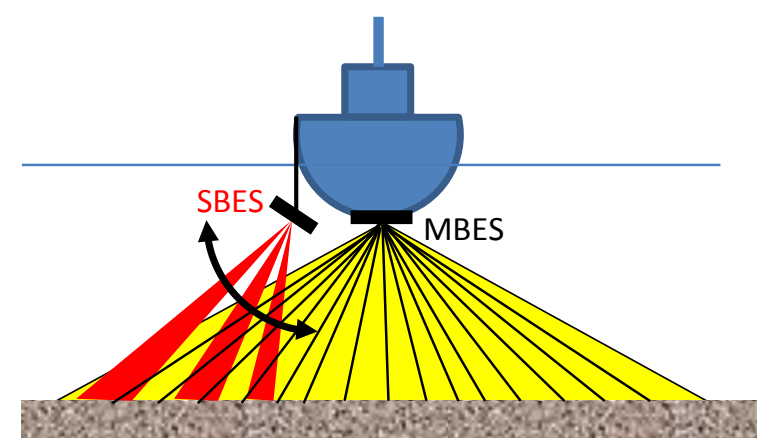

Fig.1. Schematic representation of a SBES-MBES measurement configuration for cross-calibration purposes. The tilted SBES provides a reference angular response of the seafloor to be compared with the one recorded by the MBES.

\subsection{Calibration methodology validation}

The compensation values obtained from the cross-calibration procedure correspond only to the MBES characteristics and are independent of the seabed type; hence the same exercise conducted on areas covered with different sediments should give the same results. Therefore this is a straightforward approach to verify the calibration validity, with two constraints: several reference or opportunistic calibration areas have to be available, and the at-sea duration of dedicated operations is hence increased.

\subsection{Selection of survey areas}

For the present study, a number of areas were pre-selected, all located close to the harbour of Brest (France). A first assessment of their characteristics was performed during two surveys in June and October 2014, using MBES data (EM 2040) to assess both topography and reflectivity regularity. The isotropy was checked by plotting the backscatter angular response (AR) of the MBES data for six survey lines at different azimuths with an angle step of $30^{\circ}$. Grab samples and videos were taken to assist the MBES data interpretation. The seven most promising sites were revisited in May and November 2015, following the same survey methodology. All these areas appear in Fig.2. From the last two surveys, it was concluded (Lurton et al. 2017) that: a) some of the areas are not as homogeneous as expected (Camaret \#3, and Douarnenez \#4); b) three areas (Camaret\#2, Douarnenez\#2, and Pierres Noires) are not isotropic, due to the presence of organized small-scale sand ripples; c) Pierres Noires is not stable with time and d) the area best satisfying all criteria is Carré Renard. The time stability of this area is discussed by Roche et al. (2018).

The main survey for cross-calibrating MBES data with EK60 SBES data was conducted in June 2016. Carré Renard was chosen as the main reference area; the seafloor is silty-gravelly sand mixed with coarse elements (such as maerl and shells). Camaret\#2 (fine to medium sand) and Aulne\#2 (mud colonized by slipper limpets) were selected as two opportunistic areas usable for validating the calibration results. 


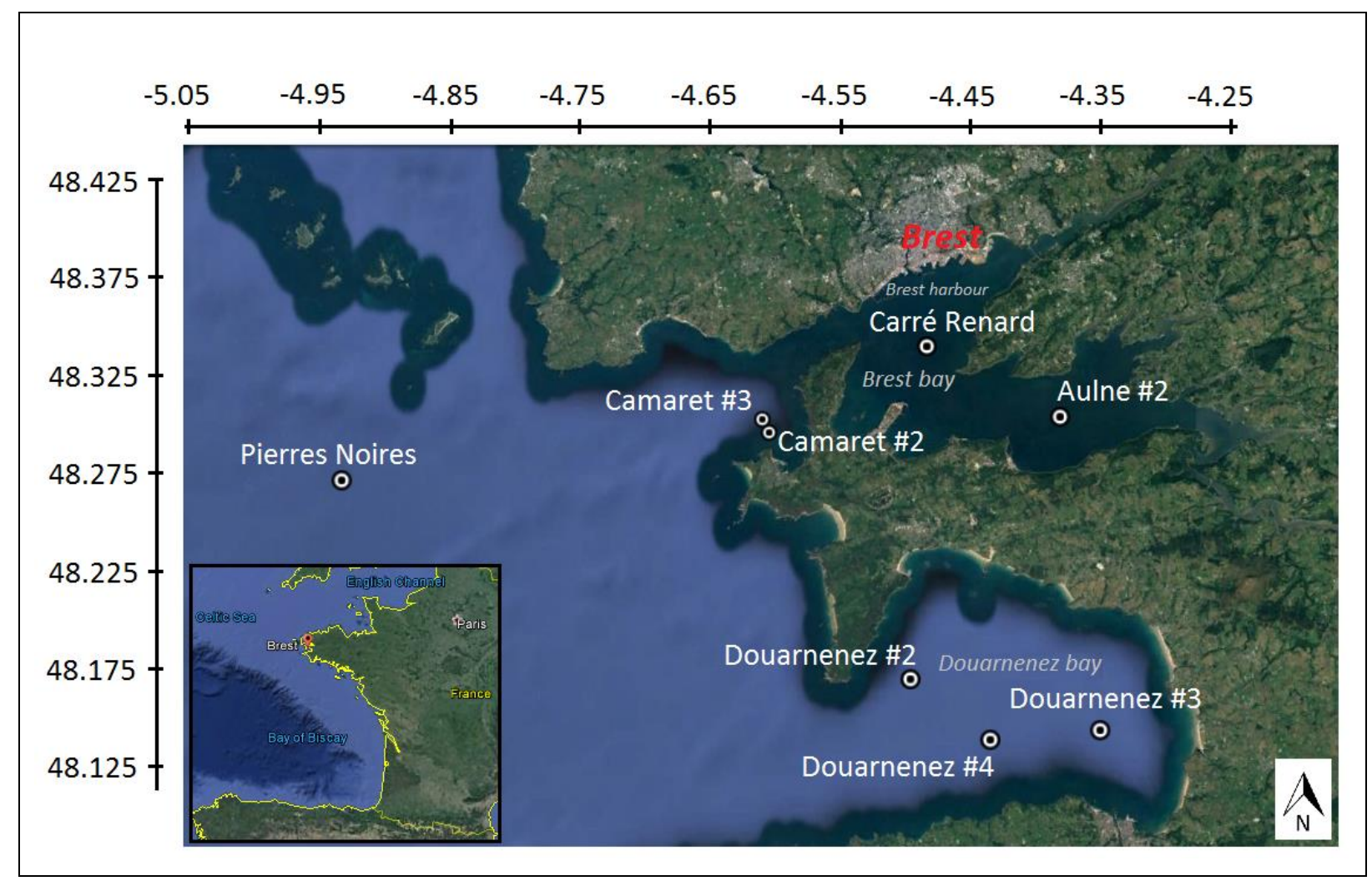

Fig.2. Geographical location of the eight surveyed areas. Carré Renard is the reference area. Camaret\#2 and Aulne\#2 are the two validation areas. The other ones (Camaret \#3, Douarnenez\#2, Douarnenez \#3, Douarnenez \#4, Pierres Noires) were only considered at an early stage of the study.

\section{MBES configurations and data processing techniques}

\subsection{MBES configurations}

The EM 2040 MBES (described in e.g. Kongsberg, 2011) considered here is a dual-Rx-head system installed on coastal R/V Thalia. It can be operated at nominal frequencies 200, 300, and $400 \mathrm{kHz}$; the results presented here refer to 200 and $300 \mathrm{kHz}$. EM 2040 can form three Tx angular sectors across-track and proposes three main modes of operation: "Central" (used in this work: only the central Tx sector is active and covers $\pm 60^{\circ}$ ), "Normal" (three Tx sectors are formed, widening the total usable aperture) and "Scanning" (of marginal interest). Although used in a majority of applications, the Normal mode was not applied here due to the increase of complexity it raises with its three overlapping Tx sectors associated to changing frequencies. For the methodological demonstration we present here, the use of Central mode was preferred, with its single frequency and Tx sector with a supposedly smooth directivity pattern. All Rx beams are roll- and pitch-stabilized. The CW pulse length for the central sector can take nominal values of 35, 70, and $150 \mu$ s for both 200 and $300 \mathrm{kHz}$. The beam spacing in reception can be "Equiangular" or "Equidistant". For all the cross-calibration operations described here, the MBES was set "Central", "Equiangular", at a 150- $\mu$ s pulse length, at both frequencies 200 and $300 \mathrm{kHz}$.

The dual-receiver structure of the MBES (Kongsberg, 2011) causes a number of specific effects on the recorded backscatter data. Each of the Rx arrays on both sides of the hull- 
mounted blister is tilted by about $40^{\circ}$ (re. horizontal). So the directivity pattern envelope of the MBES in reception (Fig.3) shows two maxima at $\pm 40^{\circ}$ (re the ship-bounded vertical axis), and slightly decreases at $0^{\circ}$ (down to about $-2 \mathrm{~dB}$ according to the constructor's measurements of directivity patterns). Moreover the zero-steering of the Rx beams happens at $\pm 40^{\circ}$, and the effect of beam aperture widening happens on both sides of this value (see $\S 4.2$, Eq.3).

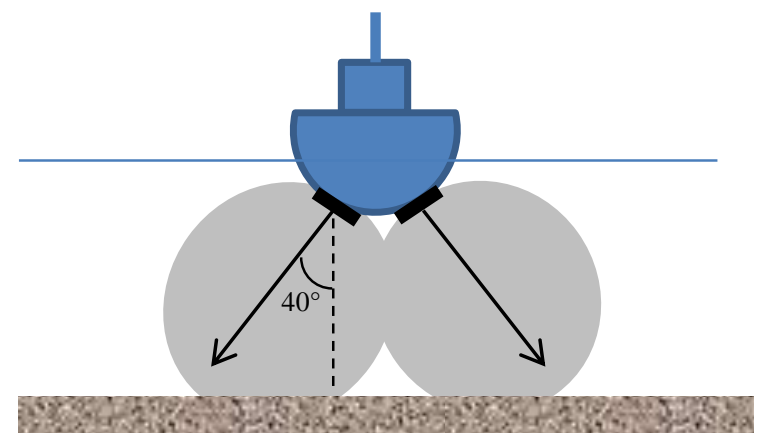

Fig.3. Schematic representation of the Rx directivity pattern envelope for the dual-head MBES used in this study.

\subsection{MBES data processing}

\subsubsection{Data format}

EM 2040 can log the seafloor backscatter strength values in two different datagram types. The first form "Beam Intensity" gives one single backscatter value per beam and ping, resulting of a moving average applied over the time series of amplitude samples and selection of the maximum average level (Hammerstad 2000). In the second form "Seabed Image", the beam amplitude time series represent a continuous set of signal samples along the bottom with a fixed slant-range step according to the sampling frequency of the MBES in its current mode.

The data presented here were processed with the Sonarscope ${ }^{\circledR}$ software suite (Augustin 2016), using the BS values from "Seabed Image" averaged in one BS value per beam. Note that the mean backscatter level is computed everywhere in the process as the average of squared signal amplitudes.

\subsubsection{Corrections}

The processing chain applied to the EM 2040 data consists in replacing the various operations applied inside the sounder for BS computation (for transmission loss and signal footprint) by more accurate compensations, mainly by accounting for the angle dependence imposed by the local topography.

\section{- Transmission loss}

The two-way transmission loss is defined classically (Lurton 2010) as:

$$
T L=40 \log R+2 \alpha R
$$

In our processing, the geometrical-divergence part (in $40 \log R$ ) is not modified; no refractioncaused impact is considered here, and the uncertainty on the slant range $R$ can be considered as negligible (Malik et al. 2018). The seawater absorption loss (two-way loss in $2 \alpha R$ ) is compensated by correcting the value of the absorption coefficient $\alpha$ from the real-time value 
used by the MBES to a more accurate one computed from measured seawater properties (see $\S 6.1$ ). For instance, the $\alpha$ magnitude at $300 \mathrm{kHz}$ is about $90 \mathrm{~dB} / \mathrm{km}$; the correction to be applied due to local variations is typically within $\pm 1 \mathrm{~dB} / \mathrm{km}$, so $\pm 0.1 \mathrm{~dB}$ for a 100 -m two-way path. Hence the impact of this absorption correction remains limited.

\section{- Insonified area}

For a MBES with Mill's cross designed arrays, the footprint area extent $A$ is defined alongtrack by the Tx sector aperture $\varphi_{a l}$; and acrosstrack by the projection on the seafloor of either the $\mathrm{Rx}$ beam aperture $\varphi_{a t}$ or the signal length $T_{e}$ (Lurton 2010). For near-vertical Rx beams, the across-track beam intersection with the seafloor $w_{N}$ (Eq.3) is smaller than the projected pulse length $w_{0}$ (Eq.2); hence the footprint width is limited by the across-track beam aperture $\varphi_{a t}$. The resulting across-track extent is the smallest of these two values (Eq.4).

$$
\begin{aligned}
& w_{O}=R\left|\sin \theta_{i}\right|\left(\sqrt{1+c T_{e} /\left(R \sin ^{2} \theta_{i}\right)}-1\right) \\
& w_{N}=R \varphi_{a t} / \cos \gamma / \cos \beta_{a t} \\
& A=R \varphi_{a l} / \cos \beta_{a l} \cdot \min \left(w_{O}, w_{N}\right)
\end{aligned}
$$

where $R$ the slant range from the sonar array to the seafloor; $\theta_{i}$ is the acrosstrack incidence angle on the seafloor, accounting for the local seafloor slope considered acrosstrack; $\beta_{a l}$ and $\beta_{a t}$ are the seafloor slope values at the footprint considered respectively alongtrack and acrosstrack. The angular apertures used here are the values given by the constructor. The across-track aperture $\varphi_{a t} / \cos \gamma$ results from the aperture change caused by beam steering. The pointing angle $\gamma$ is defined here (case of a dual-head EM2040) as the beamforming angle off the Rx array axis tilted by approximately $40^{\circ}$ on each hull side. Moreover $\gamma$ has to include the compensation of the ship's motion when the MBES is used in a roll-compensated mode, which is normally the case.

The detailed formulas of the constructor's model for the insonified area (Hammerstad 2000) are simpler than the ones above, and do not account for the local seafloor slopes. Written with the same notations as ours, they come as:

$$
\begin{aligned}
& w_{O}=c T_{e} / \sin \theta \\
& w_{N}=R \varphi_{a t} / \cos \gamma \\
& A=R \varphi_{a l} \cdot \min \left(w_{O}, w_{N}\right)
\end{aligned}
$$

These simplified formulas (using a generic vertical-referenced angle $\theta$ ) are indeed appropriate for the real-time computations applied in the MBES, since they require no preliminary knowledge of the actual seafloor topography.

In the processing presented here, the real-time footprint extent compensation given by Eqs.5-7 was replaced by the one computed from Eqs.2-4, where all the angle values considered in the computations accounted for (1) the ship's motion and (2) the seafloor local topography. The latter implies that, at each sounding point, the local slope has to be determined from the previously-computed digital terrain model. In the particular cases presented here, this does not lead to dramatic impacts in the results, since the ship's angular motion remained within $\pm 1^{\circ}$, and the local seabed slopes nowhere exceeded $\pm 2.5^{\circ}$. A constant-SVP assumption was made, which is a valid approximation considering the local seawater homogeneity observed during the various operations at sea.

It is also important that a distinction is made between the seafloor-related incidence angles (for the backscatter angular dependence) and the angles referenced to the MBES array (used 
in the sonar directivity pattern). The former angles are used in a first processing step, to compute the difference between EM2040 backscatter data and reference values determined from the SBES measurements. The latter angles are considered in a second stage when averaging these differential data, leading to the determination of the sonar angular response.

It should also be noted that the effective pulse length considered in our work differs from the nominal pulse length given by the constructor at the time of the data acquisition (using the Kongsberg acquisition software SIS version 4.3.0). We considered an effective value of 0.68 times the nominal pulse length, computed from previous results (not published) of in-tank test measurements of an EM 2040 on a reference sphere target.

\section{SBES configurations, calibration, and data processing techniques}

\subsection{SBES configurations}

The SBES used in this work is a Simrad EK60 split-beam echosounder with a built-in calibration functionality. It was operated at 200 and $333 \mathrm{kHz}$; impact of the difference of 333 $\mathrm{kHz}$ with the nominal $300 \mathrm{kHz}$ of the MBES is discussed in Appendix 1. At both frequencies the one-way beam aperture is approximately $7^{\circ}$. The available pulse lengths for these frequencies are 64, 128, 256, 512 and $1024 \mu \mathrm{s}$; the pulse length of $256 \mu$ s was selected here.

The EK60 transducers were installed on a vertical pole, fixed on the starboard side of $R / V$ Thalia (Fig.1). A swivelling device (Pan \& Tilt) was attached at the pole tip and the two EK60 transducers adapted on it (Fig.3). The swivelling device was remotely controlled from the ship, rotating the transducers both in the horizontal and vertical planes. The transducers could be steered at any required angle with a $1^{\circ}$ step. For this study, the tilt angle of the EK60 varied between $0^{\circ}$ and $60^{\circ}$ with a step of $3^{\circ}$. The transducer immersion was approximately $3.5 \mathrm{~m}$, corresponding to the Thalia draft.

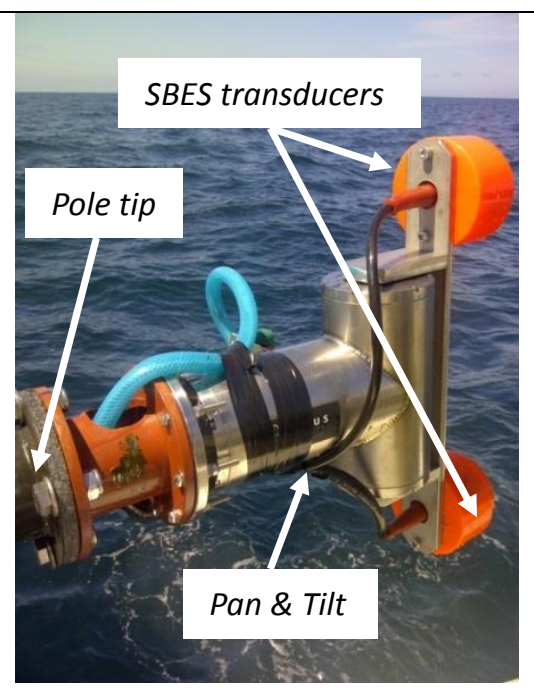

Fig.4. The Pan \& Tilt system fixed at the tip of the pole, with the two EK60 transducers attached.

\subsection{EK60 calibration}

The SBES calibration principle (Simmonds and McLennan 2005; Demer et al. 2015) is to measure directly the sonar's combined Tx-Rx response on a controlled point target with accurately known target strength. A portable sounder may be deployed in a test tank; however hull-mounted systems are much more usual, and in this case the carrier vessel must be at 
quayside or anchored in calm sea conditions. Basically, the procedure consists of recording and measuring the signal backscattered by the target positioned below the transducer looking downward, at controlled range and angle. The range is readily determined by the two-way travel time of the signal; the angle relative to the sounder beam axis is estimated from the interferometric "split-beam" measurement of the phase differences between the four quarters of the transducer plate. The strategy is to move the target at a fixed depth in the horizontal plane in order to cover the complete beam aperture - at least its main lobe; this procedure makes it possible to estimate the directivity lobe pattern. The reference targets are full-metal spheres with very accurate dimensions and alloy composition (tungsten-carbide-cobalt); their sizes are adapted to various frequency ranges.

The measured target strength (TS), obtained after compensation from the sounder directivity pattern, is compared to its nominal value; the latter is given by a theoretical model parameterized by the measurement conditions. The correction to be applied to the sounder sensitivity is the level bias obtained from this comparison.

A SBES calibration dataset (see an example in Table 1) comprises the absolute response level $\left(G_{0}\right)$ measured on the lobe axis; the pulse shape adjustment factor $\left(S_{a}\right)$ obtained from the signal intensity integrated over the actual pulse duration; the RMS variability of the measured data fitted to the directivity model; and the one-way $3 \mathrm{~dB}$ beamwidth of the lobe in both athwartship and alongship direction. For our case study, the SBES calibration took place in Brest harbour with both systems $(200$ and $333 \mathrm{kHz})$ installed on $R / V$ Thalia, using respectively $38.1-\mathrm{mm}$ and $22-\mathrm{mm}$ diameter spheres. The results are summarized in Table 1.

Table 1. EK60 SBES calibration values (June 2016; $\mathrm{T}=16.5^{\circ} \mathrm{C} ; \mathrm{S}=34.5 \mathrm{PSU} ; \mathrm{c}=1510 \mathrm{~m} / \mathrm{s}$ )

\begin{tabular}{|c|c|c|c|c|c|c|c|}
\hline $\begin{array}{c}\text { Frequency } \\
(\mathrm{kHz})\end{array}$ & $\begin{array}{c}\text { Pulse } \\
\text { length } \\
(\mu \mathrm{s})\end{array}$ & $\begin{array}{c}\text { Sphere } \\
\text { diameter } \\
(\mathrm{mm})\end{array}$ & $G_{0}(\mathrm{~dB})$ & $\begin{array}{c}S_{a, \text { corr }} \\
(\mathrm{dB})\end{array}$ & $\begin{array}{c}\text { RMS } \\
(\mathrm{dB})\end{array}$ & $\begin{array}{c}\text { Athwartship } \\
\text { beamwidth }\left(^{\circ}\right)\end{array}$ & $\begin{array}{c}\text { Alongship } \\
\text { beamwidth }\left({ }^{\circ}\right)\end{array}$ \\
\hline 200 & 256 & 38.1 & 26.67 & -0.37 & 0.25 & 7.5 & 7.4 \\
\hline 333 & 256 & 22 & 27.07 & -0.38 & 0.44 & 7.4 & 7.5 \\
\hline
\end{tabular}

\subsection{EK60 data processing}

Simrad SBES data are logged in '.raw' files containing received signal samples (power and electrical phase angles) and echosounder configuration parameters.

\subsubsection{Converting power to volume backscattering strength}

The first step converts the raw signal power values to volume backscattering strength $S_{v}$ (in $\mathrm{dB}$ ) which is the classical output of fishery echosounders:

$$
S_{v}=10 \log P_{r}+20 \log R+2 \alpha R-10 \log \frac{P_{t} \lambda^{2} c}{32 \pi^{2}}-2 G_{0}-10 \log T-2 S_{a}-\psi
$$

where $R$ is the sonar-target range $(\mathrm{m}) ; \alpha$ the absorption coefficient $(\mathrm{dB} / \mathrm{m}) ; P_{t}$ and $P_{r}$ the transmitted and received power $(\mathrm{W}) ; c$ the sound velocity $(\mathrm{m} / \mathrm{s}) ; T$ the pulse length $(\mathrm{s}) ; \lambda$ the wavelength (m); $\psi$ the two-way equivalent aperture (solid angle in $\mathrm{dB}$ re $1 \mathrm{sr}$ ); $G_{0}$ the on-axis calibrating gain $(\mathrm{dB}) ; S_{a}$ the effective pulse length correction factor $(\mathrm{dB})$.

\subsubsection{Corrections}

A number of corrections have to be applied in the data post-processing. Some of them are aimed at correcting inaccurate environmental parameter values used in real-time processing 
(e.g. absorption coefficient) and others result from installation limitations (e.g. uncertainty in the real tilt angle of EK60).

- Roll: the ship's roll is logged in the EK60 'Sample' datagram, with one roll value per ping. For our system configuration (EK60 steered to starboard), positive roll values (bridge tilting down on starboard) correspond to steeper incidence angles.

- Transducer angle shift: the transducer angular position is controlled by the Pan \& Tilt device, which is set according to a reference geometric angle (ideally $0^{\circ}$ i.e. the vertical axis). Due to the difficulty of a direct geometric measurement, an indirect method of angular referencing was applied, using the SBES field data, and based on the assumption (checked from the local bathymetry data) of an average flat horizontal surveyed area. For each tilt angle of the transducer, ranges to the bottom are estimated from the split-beam interferometric data, using the time samples selected in the bottom detection procedure (see §5.3.3). Then these bottom-range values obtained for all tilt angles are corrected for roll and tide, and used to search for the angle shift (within a given range, typically $-10^{\circ}$ to $10^{\circ}$ ) minimizing the dispersion of depth values around the average depth over the area; the obtained value is taken as the best estimate of the installation angle bias. See an illustration of the method and results in Fig.5. This correction method makes it possible to compensate for an angular bias in the transducer mounting, and for a permanent tilt of the ship e.g. due to side wind; ideally it should be determined for each survey line.

Finally the actual incidence angle (assuming flat seabed) is given by the value of the Pan \& Tilt setting, corrected from roll (time dependent) and installation angle shift (stable).
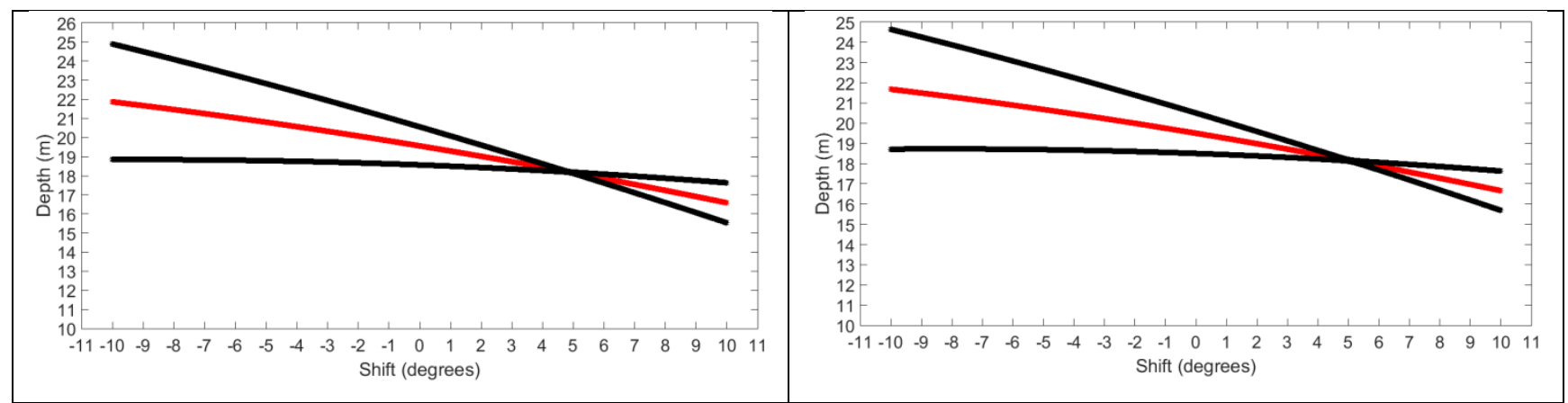

Fig.5. Depth $v s$ estimated angle shift in the tilt angle of EK60. Mean depth (red curve) and \pm standard deviation (black curves) of the calculation for each shift value for (left) North-South and (right) SouthNorth direction. The estimated installation angle shift (corresponding to the pseudo-crossing point, minimizing the depth dispersion) is here around $5^{\circ}$.

\subsubsection{Bottom detection}

A critical step in the processing is the bottom detection since it determines the backscatter samples to be considered within each beam time series for calculating the BS value. Here the bottom was detected using one of two classical methods (Lurton 2010) depending on the incidence angle:

- Maximum amplitude at normal and near-normal incidence. First, a restricted range interval is defined around the probable bottom echo, where the athwartship in-beam angle $\Phi$ and $S v$ vs range are used to calculate the Center of Gravity (CoG, computed on natural intensity values) of the $S v$ data; an example is shown in Figs. 6a and 6b. In this particular case, Fig.6a ( $\Phi$ vs range) shows no phase-ramp behaviour, justifying the choice of a CoGbased bottom detection. For BS analysis, we considered the average of all samples with incidence angle falling within $\pm 1^{\circ}$ from the $\mathrm{CoG}$ (with a minimum of three samples); see Fig.6 for illustration. 


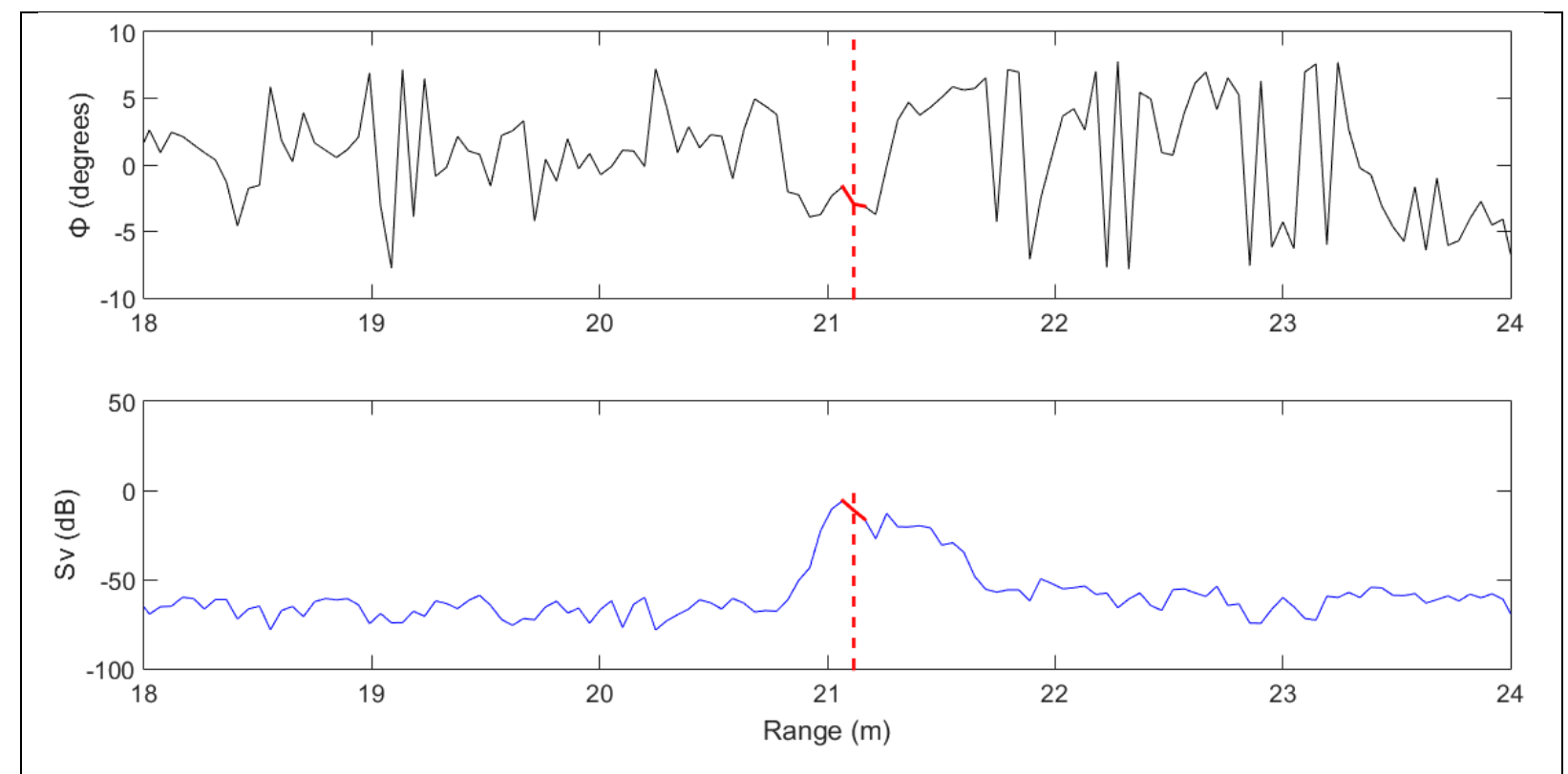

Fig.6. Original signal for a near-normal incidence angle: (top) in-beam angle $\Phi$ vs range; (bottom) $S v$ vs range; (red dashed lines) bottom detection range; (red solid lines) samples finally selected for backscatter analysis.

- Zero-crossing phase angle at oblique incidence. Like in the previous case, the first step is to find the $S v$ CoG. The phase samples falling within $\pm 3^{\circ}$ from the $\mathrm{CoG}$ are fitted with a second-order polynomial (Fig.7 top) used to determine the instant of null phase-difference while avoiding wrong zero-crossing estimates due to noise fluctuations. The bottom samples used for backscatter are those falling within $\pm 1^{\circ}$ around the zero-crossing (Fig.7).

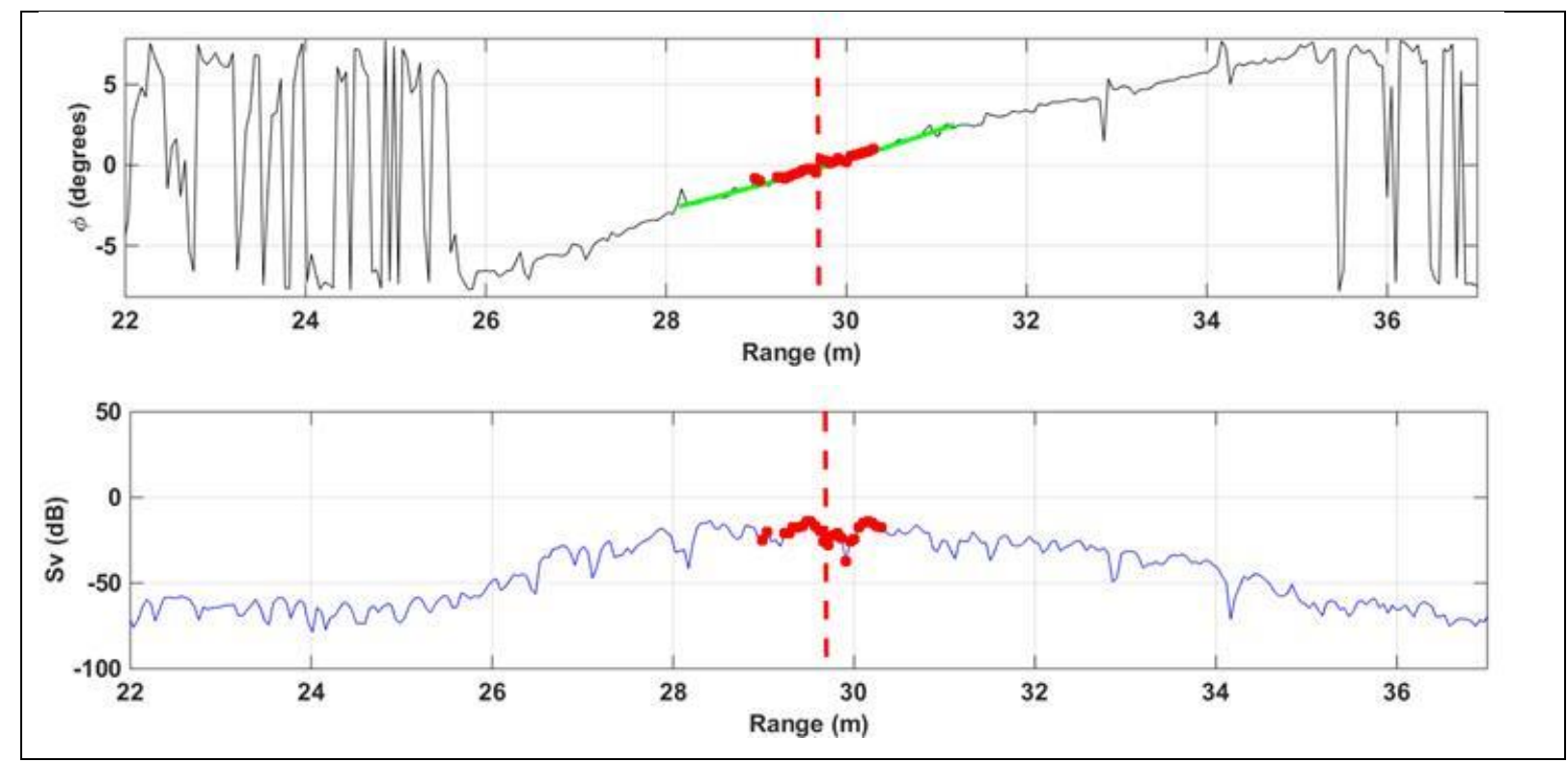

Fig.7. Original signal for oblique incidence angle: (top) in-beam angle $\Phi$ vs range; (bottom) $S v$ vs range; (green line) fitted $2^{\text {nd }}$-order polynomial; (red dashed lines) bottom detection range; (red dots) samples finally selected for subsequent backscatter analysis.

\subsubsection{From volume to interface backscattering strength}

The $S v$ data must be transformed into interface backscatter strength values by compensating for the insonified area extent. The resulting BS values are then corrected for the SBES directivity pattern. 
At oblique angles, the across-track width $w_{O}$ of the active footprint is determined by the effective transmit pulse length $T_{e}=T_{s} 10^{\frac{S_{a, c o r r}}{5}}$ ( $T_{s}$ being the nominal pulse length) projected on the seafloor (Eq.9). At near-vertical incidence angles, the across-track beam intersection with the seafloor becomes smaller than the projected pulse length; hence the footprint width is limited (Eq.10) by the effective two-way across-track beam aperture $\varphi_{a t 2}$. The resulting across-track extent is the smallest of these two values (Eq.11).

$$
\begin{gathered}
w_{O}=R|\sin (\Phi+\theta)|\left(\sqrt{1+\frac{c T_{e}}{R \sin ^{2}(\Phi+\theta)}}-1\right) \\
w_{N}=\varphi_{a t 2} \frac{R}{\cos \theta} \\
A=\varphi_{a l 2} R \cdot \min \left(w_{O}, w_{N}\right)
\end{gathered}
$$

The effective -or equivalent- aperture is the width of an ideal directivity pattern integrating the same amount of intensity (Lurton 2010); this beam angular effective aperture can be adjusted proportionally to the current sound velocity (Bodholt 2002). The effective two-way apertures $\varphi_{\text {at } 2}$ and $\varphi_{\text {al2 }}$ (respectively across-track and along-track) are estimated here by integrating the squared directivity patterns (measured by a reference hydrophone) over their main lobe. A restricted angle sector $\left( \pm 10^{\circ}\right)$ is sufficient for this purpose, since for EK60 transducers the two-way sidelobe level is low $(<-50 \mathrm{~dB})$ and negligibly contributes to the angular integration. The original measurements of beam patterns are provided by the constructor in the EK60 transducer datasheet, and have been checked in the Ifremer test-tank (Table 2).

Table 2. Beam widths estimated for SBES insonified area calculation. The three first columns of beamwidth values are provided by the constructor based on test-tank measurements in fresh water. The last column gives the results of measurements in the Ifremer's seawater tank.

\begin{tabular}{|c|c|c|c|c|c|}
\hline $\begin{array}{c}\text { Frequency } \\
\text { (kHz) }\end{array}$ & Direction & $\begin{array}{c}\text { Measured one-way } \\
\text { 3dB beamwidth } \\
\text { Fresh water } \\
\mathrm{T}^{\circ}=20^{\circ} \mathrm{C} \\
\mathrm{c}=1482 \mathrm{~m} / \mathrm{s}\end{array}$ & $\begin{array}{c}\text { Two-way 3dB } \\
\text { beamwidth } \\
\text { Fresh water } \\
\mathrm{T}^{\circ}=20^{\circ} \mathrm{C} \\
\mathrm{c}=1482 \mathrm{~m} / \mathrm{s}\end{array}$ & $\begin{array}{c}\text { Effective two-way } \\
\text { beamwidth } \\
\text { Fresh water } \\
\mathrm{T}^{\circ}=20^{\circ} \mathrm{C} \\
\mathrm{c}=1482 \mathrm{~m} / \mathrm{s}\end{array}$ & $\begin{array}{c}\text { Effective two-way } \\
\text { beamwidth } \\
\text { Seawater } \\
\mathrm{T}^{\circ}=16.5^{\circ} \mathrm{C} \\
\mathrm{S}=34.5 \mathrm{PSU} \\
\mathrm{c}=1510 \mathrm{~m} / \mathrm{s}\end{array}$ \\
\hline 200 & along & $7.3^{\circ}$ & $5.2^{\circ}$ & $5.5^{\circ}$ & $5.6^{\circ}$ \\
\hline 200 & athwart & $7.4^{\circ}$ & $5.3^{\circ}$ & $5.6^{\circ}$ & $5.7^{\circ}$ \\
\hline 333 & along & $7.4^{\circ}$ & $5.3^{\circ}$ & $5.6^{\circ}$ & $5.7^{\circ}$ \\
\hline 333 & athwart & $7.3^{\circ}$ & $5.2^{\circ}$ & $5.5^{\circ}$ & $5.6^{\circ}$ \\
\hline
\end{tabular}

\section{- Beam pattern}

The EK60 beam pattern is approximated, for both frequencies 200 and $333 \mathrm{kHz}$, by (Demer et al. 2015):

$$
D\left(\beta_{a t}, \beta_{a l}\right)=-6.0206\left[x^{2}+y^{2}-0.18 x^{2} y^{2}\right]
$$

with $x=\frac{2 \beta_{a t}}{\gamma_{a t 1}}$ and $y=\frac{2 \beta_{a l}}{\gamma_{a l 1}}$, where $\beta_{a t}$ and $\beta_{a l}$ are the athwart- and along-ship angle values referenced to the beam axis, and $\gamma_{a t 1}$ and $\gamma_{a l 1}$ are the one-way 3-dB aperture values. Practically the along-track effect is negligible, and is not considered here. The $B S$ value is finally calculated as: 


$$
B S=S_{v}+\psi+20 \log R+10 \log \left(\frac{c T_{e}}{2}\right)-10 \log A-D
$$

\subsubsection{Final BS averaging}

The purpose of the SBES data processing is to get one BS value per nominal incidence angle (i.e. transducer tilt value per survey line). This implies to select for each ping the signal time samples corresponding to the nominal incidence angle of the current line. One BS value is calculated for each ping; the number of samples averaged in this respect depends on the bottom-detection procedure, as described in $\$ 5.3 .3$. Then the per-ping BS values are averaged along the survey line, excluding the pings with actual incidence angles beyond $\pm 1^{\circ}$ from the nominal incidence angle of the line; in this respect it is better to conduct the survey with a minimum roll motion, to maximize the number of pings eligible to averaging. This last operation provides one BS value per nominal incidence angle.

\section{Cross-calibration}

\subsection{Absorption coefficient impact}

In the cross-calibration process, it is paramount that consistent absorption values are applied to data from both sonars. Table 3 shows the theoretical absorption coefficient values (Francois-Garrison 1982) using salinity and temperature profiles obtained from field measurements (ship's thermosalinograph and temperature-depth probes) completed by salinity profiles from an oceanographic database. When necessary the data (both of EM 2040 and EK60) were corrected in post-processing based on the values of Table 3.

Table 3. Values of calculated absorption coefficients (in $\mathrm{dB} / \mathrm{km}$ )

\begin{tabular}{|c|c|c|}
\hline Frequency $(\mathrm{kHz})$ & Carré Renard & Camaret\#2 \\
\hline 333 & 93.4 & 93.9 \\
\hline 300 & 86.8 & 87.2 \\
\hline 200 & 66.6 & 66.9 \\
\hline
\end{tabular}

\subsection{Cross-calibrating MBES and SBES on Carré Renard}

A preliminary step is to identify in the reference area the survey line providing the most reliable results. Data recorded on Carré Renard (June 2016) are shown in Fig.8. The backscatter level image is uniform and the bathymetry is fairly flat (depth range less than 2 $\mathrm{m})$. The sediment is sand with silt, gravel, maerl and shells; the interface is colonized by brittle stars. Added to the reflectivity image uniformity, everything suggests that the local sediment variability has negligible effects and that Carré Renard is a satisfactorily flat, homogeneous, isotropic and stable area usable as a reference for backscatter calibration (Roche et al. 2018). Considering the average BS dependence on azimuthal angle, the variations per incidence angle (see Fig.3 in Lurton et al. 2017) were found to be within $\pm 0.5 \mathrm{~dB}$ and hence considered as negligible.

For the present study, the NS lines were selected for the calibration procedure since they provide the best stability and symmetry in angular backscatter, compared to other azimuth angles (the detailed comparisons are not shown here), and presumably cover the most homogenous part of the area. The bathymetry of one typical NS line is presented in Fig.9, with backscatter images at 300 and $200 \mathrm{kHz}$. The depth range is less than $1 \mathrm{~m}$, while both 
reflectivity images are uniform. The survey line length was $425 \mathrm{~m}$, the swath width $80 \mathrm{~m}$, the survey speed $2.4 \mathrm{~m} / \mathrm{s}$, and the number of pings 349; the roll angles stayed within $\pm 1^{\circ}$.

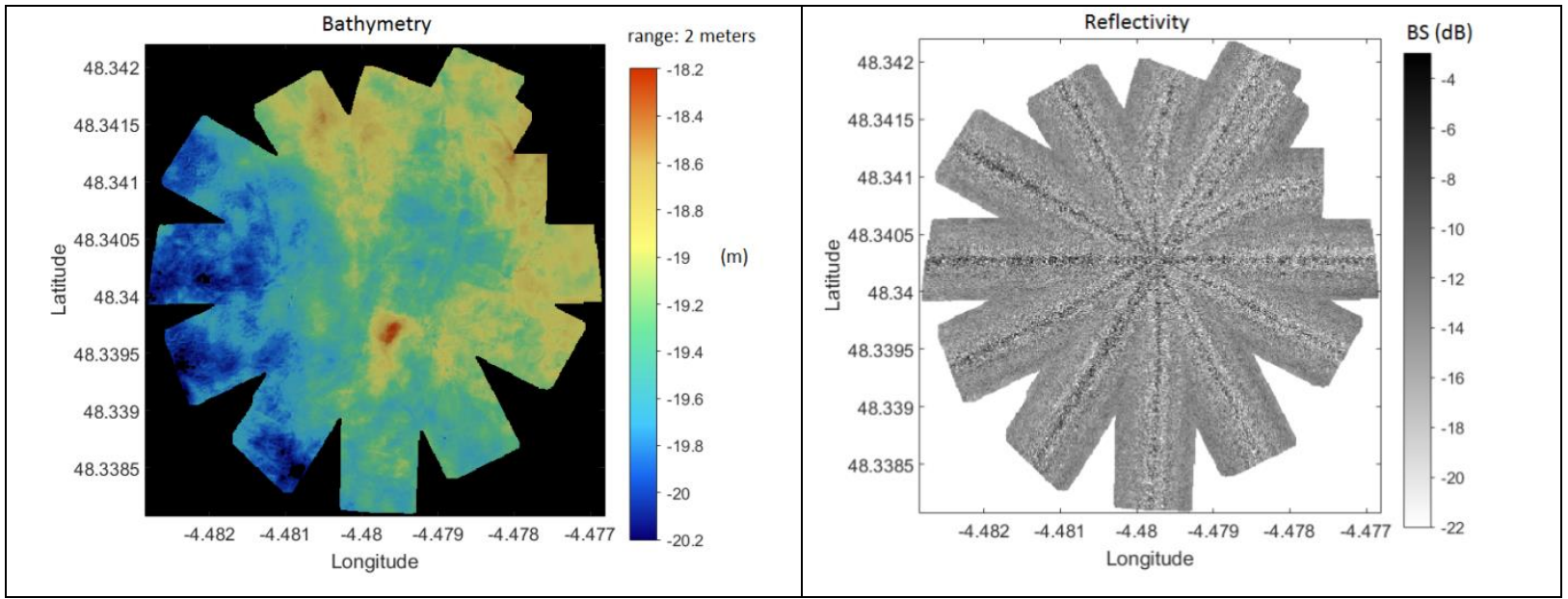

Fig.8. Preliminary configuration data (June 2016) for Carré Renard: (left) bathymetry map (tide corrected from the Brest tidal station); (right) backscatter level.

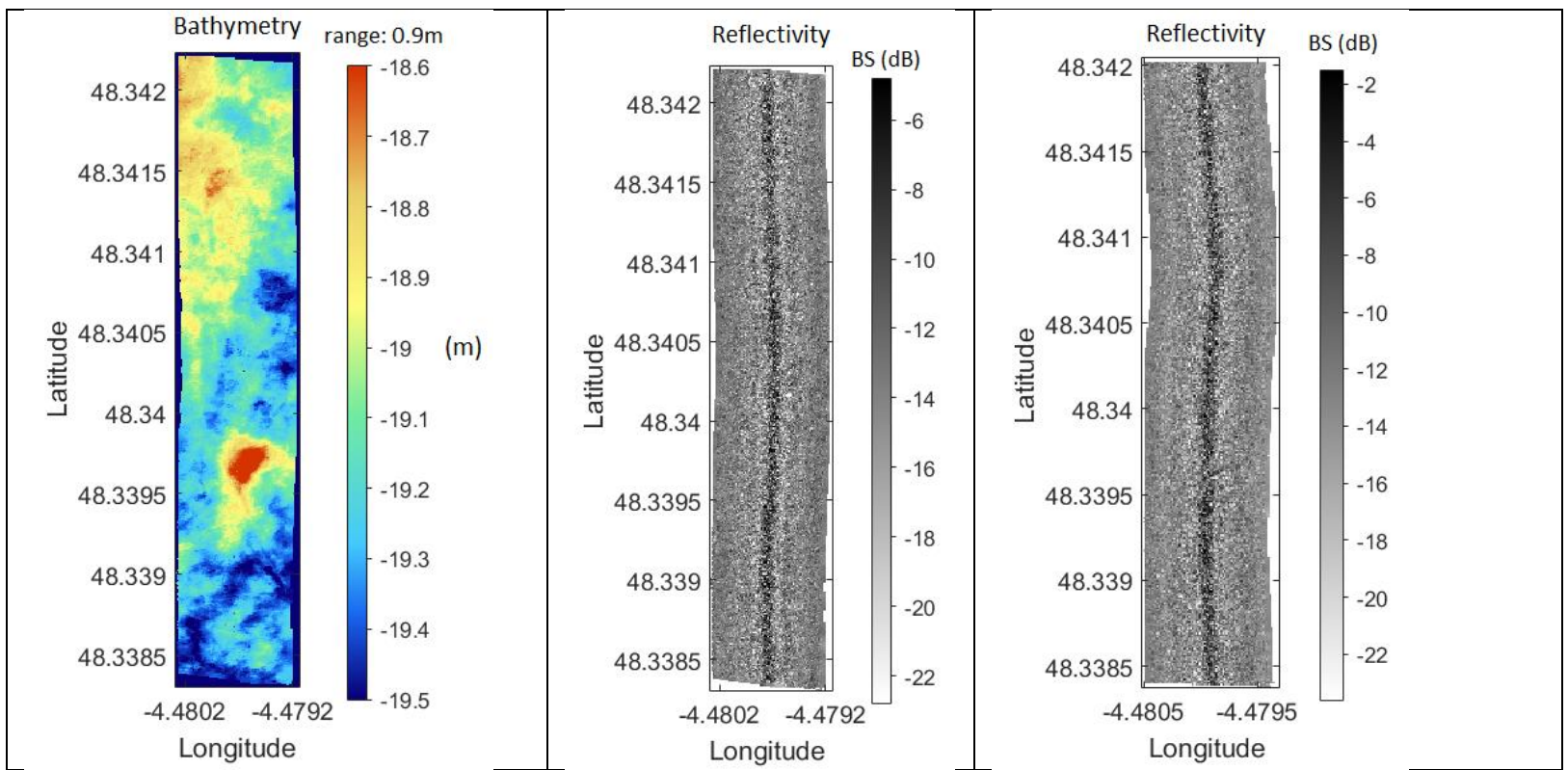

Fig.9. Mapping results for one North-South line on Carré Renard: (left) bathymetry $(300 \mathrm{kHz})$; reflectivity at (center) $300 \mathrm{kHz}$ and (right) $200 \mathrm{kHz}$.

The second step is to determine the representative AR of the MBES. All available data recorded on NS survey lines were averaged separately for $300 \mathrm{kHz}$ (Fig.10 top) and $200 \mathrm{kHz}$ (Fig.11 top). The resulting curves are from 7 different lines at $300 \mathrm{kHz}$ and 4 ones at $200 \mathrm{kHz}$. The BS variations between the different lines are less than $0.5 \mathrm{~dB}$; hence the MBES measurement stability is excellent.

The third step is to determine the reference backscatter data measured by the SBES. An important parameter to be determined in post-processing is the transducer tilt angle bias (see §5.3.2). The shift values were found to be $4.87^{\circ}$ for NS lines (Fig.5 top) and $5.06^{\circ}$ for SN lines (Fig. 5 bottom) so an average value of $5.0^{\circ}$ was retained. 
On Carré Renard a total of 42 lines of EK60 (21 per direction) are available, with SBES tilt angles from $0^{\circ}$ to $60^{\circ}$ by $3^{\circ}$. To determine the transition angle between the two bottomdetection methods (amplitude or phase, see §5.3.3), the interferometric and amplitude data were visually compared: at both frequencies (333 and $200 \mathrm{kHz}$ ), it was observed that the phase ramp is stabilized only beyond $20^{\circ}$; this value was taken as the detection-method transition angle. Since EK60 insonifies either the port or starboard side of each line, the data are processed separately for each direction (NS $\left.0^{\circ}: 60^{\circ}, \mathrm{SN}-60^{\circ}: 0^{\circ}\right)$ resulting in one BS value per incidence angle (see Fig. 10 top at $333 \mathrm{kHz}$ and Fig. 11 top at $200 \mathrm{kHz}$ ). Despite its data density (a $3^{\circ}$ angle step), this series of points is not fully adequate for direct comparison with the EM 2040 data sampled every $1^{\circ}$ over $\left[-60^{\circ} 60^{\circ}\right]$. As an intermediate step, the EK60 BS results are fitted with the Generic Seafloor Acoustic Backscatter (GSAB) model (Lamarche et al. 2011) over the complete angular range. In its simplest version, this model represents the BS angular dependence as a combination of a Gaussian law at steep angles and Lambert-like law at grazing angles:

$$
B S(\theta)=10 \log \left[A \exp \left(-\frac{\theta^{2}}{2 B^{2}}\right)+C \cos ^{D} \theta\right]
$$

See Lamarche et al. (2011) for a detailed interpretation of the parameters $A, B, C, D$. The root mean squared errors (RMSE) of curve fitting for the EK60 values at 333 and $200 \mathrm{kHz}$ (Figs. 10 and 11 top) are $0.24 \mathrm{~dB}$ and $0.17 \mathrm{~dB}$ respectively. The resulting GSAB parameters values are shown in Table 4.

Table 4. GSAB model (Eq.14) parameters values after fitting the model to the EK60 data (see Fig.10 \& 11 top) and RMS error.

\begin{tabular}{|l|c|c|c|c|c|}
\hline & \multicolumn{4}{|c|}{ GSAB parameters values } & \multirow{2}{*}{ RMSE (dB) } \\
\cline { 1 - 5 } $\begin{array}{l}\text { Frequency } \\
(\mathrm{kHz})\end{array}$ & $10 \log A(\mathrm{~dB})$ & $B\left(^{\circ}\right)$ & $10 \log C(\mathrm{~dB})$ & $D$ & 0.24 \\
\hline 333 & -7.74 & 10.51 & -10.66 & 1.49 & 0.17 \\
\hline 200 & -8.58 & 10.55 & -11.59 & 1.37 & \\
\hline
\end{tabular}




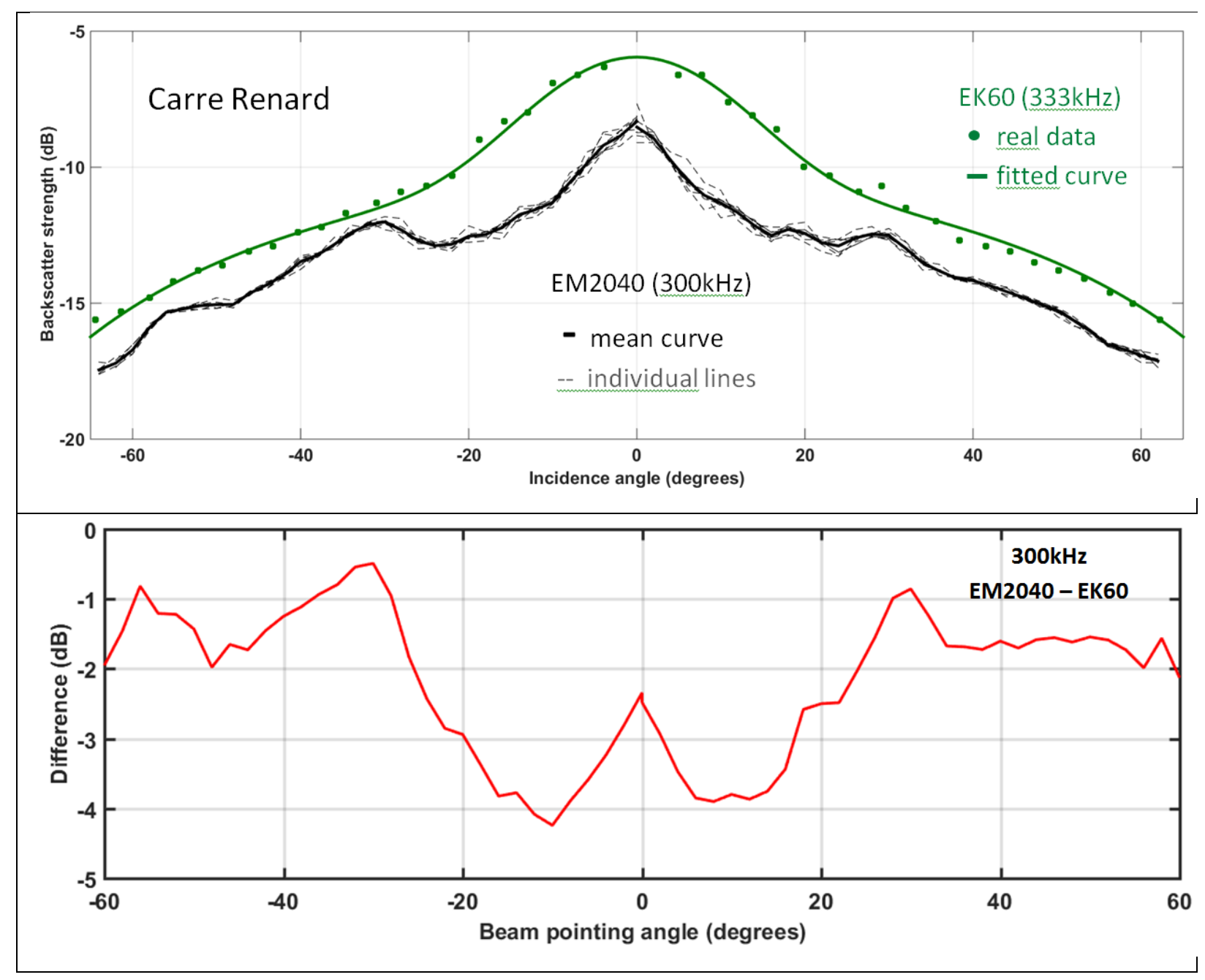

Fig.10.: Cross-calibration processing results on Carré Renard at $300 \mathrm{kHz}$. (Top) BS values (green dots) obtained from EK60 data $(333 \mathrm{kHz})$ and fitting of the GSAB model (green solid curve); mean AR curve (solid black line) of EM $2040(300 \mathrm{kHz})$ and data from individual lines (dashed grey lines) in the same direction. (Bottom) Difference curve obtained by subtracting EK60 values from EM 2040 values. 

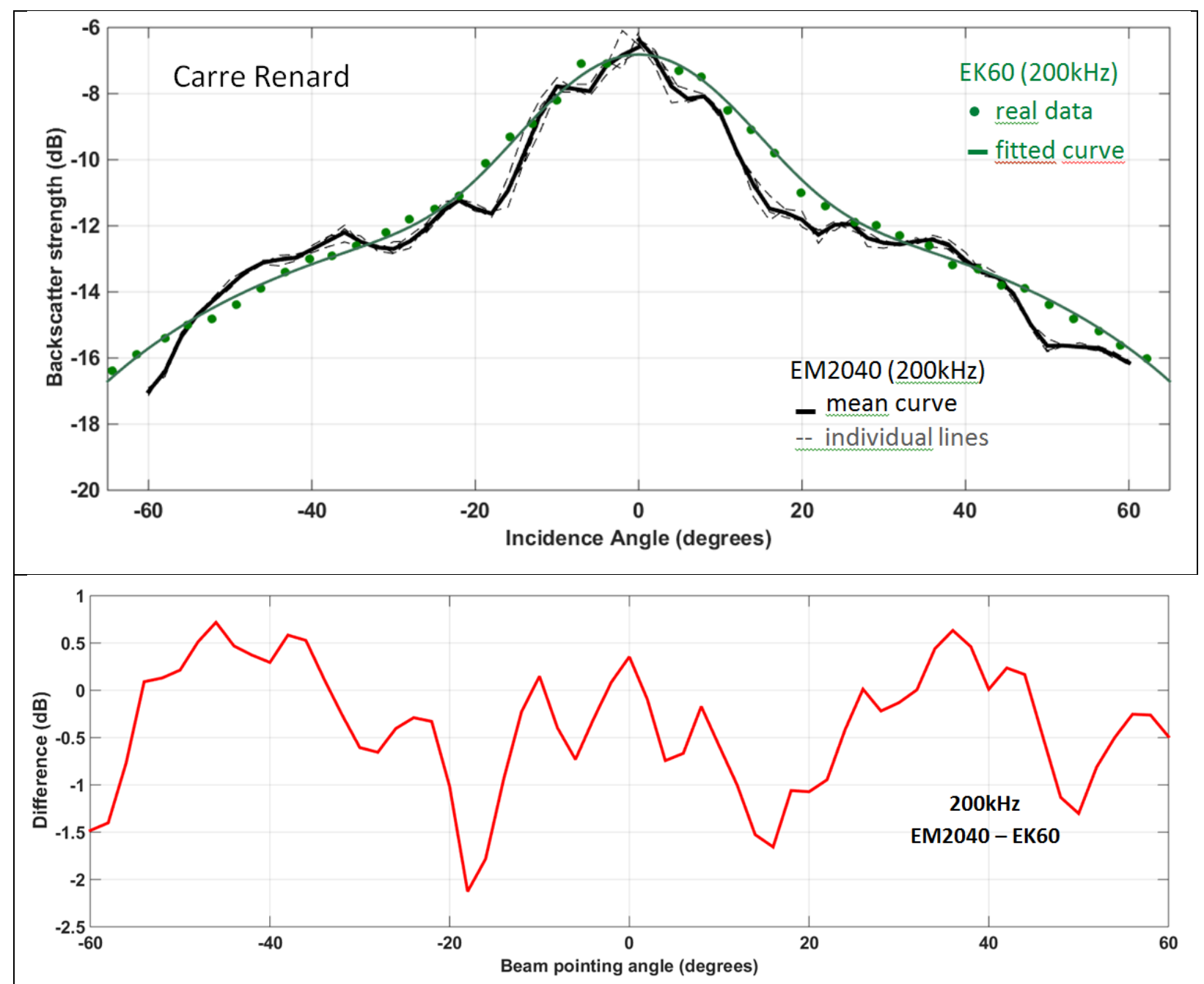

Fig.11. Cross-calibration processing results on Carré Renard at $200 \mathrm{kHz}$. (Top) BS values (green dots) obtained from EK60 data and fit of the GSAB model (green solid curve); mean AR curve (solid black line) of EM 2040 and data from all lines (dashed grey lines) in the same direction. (Bottom). Difference curve obtained by subtracting EK60 values from EM 2040 values.

The final step is to estimate the AR difference between EM 2040 data and EK60 reference for each frequency: the results are plotted in Fig.10 bottom $(333 \mathrm{kHz})$ and Fig. 11 bottom $(200 \mathrm{kHz})$. These residuals can be used to correct the complete dataset for this specific EM 2040 configuration. The obtained results show biases roughly ranging -2 to $+0.5 \mathrm{~dB}$ at $200 \mathrm{kHz}$, and -4 to $-0.5 \mathrm{~dB}$ at $300 \mathrm{kHz}$. Such magnitudes are obviously very significant, and emphasize the interest of applying an intensity-calibration procedure to this model of MBES. 


\subsection{Calibration checking on Camaret\#2 area}

A straightforward way to validate the calibration results is to compare the compensation curves obtained on various geological facies: in principle they should be identical. Unfortunately, no high-density EK60 measurements were conducted on other areas as thoroughly as on Carré Renard. Hence a simpler approach was used for the verification: two areas (Camaret\#2 and Aulne\#2, see Fig.2, with sediment types different from Carré Renard) were surveyed to identify sub-areas prone to provide potentially useful EK60 data. The EM 2040 compensation curve (Fig.10 and 11) derived at Carré Renard was applied to correct the MBES data taken on Camaret\#2 and Aulne\#2; these corrected data were compared with the calibrated EK60 measurements logged on these sites for a limited number of tilt angles. The match of these two independent results should validate the EM 2040 calibration procedure.

The Camaret\#2 area has been regularly surveyed over the recent years, being located close to a bathymetry reference area. It consists of sand with grain size ranging from fine to medium. The depth varies moderately on the area (see Fig.12 left). Most importantly, significant changes in backscatter level on several patches (Fig.12 right) reveal either non-homogeneous seabed nature or the presence of topography anomalies. Due to strong tide currents, smallscale ripples are formed on the seabed, with a significant impact on backscatter level when surveying at different azimuthal angles (see Fig.4 in Lurton et al. 2017); such features are found on many sandy areas around Brest.

The June 2016 survey aimed to identify a line with minimal BS fluctuations usable for testing the calibration methodology. The most homogeneous lines were found to be oriented W-E. Fig. 13 presents the bathymetry and backscatter on such a WE line example: the survey line length was $208 \mathrm{~m}$, the swath width $85 \mathrm{~m}$, the survey speed $1.67 \mathrm{~m} / \mathrm{s}$, the roll angles within $\pm 1^{\circ}$, and the number of pings 248 . This line was surveyed repeatedly for various modes of the EM 2040. The data analysis was restricted to the flat part of the area, within longitudes [$4.6025^{\circ}-4.6015^{\circ}$; , however, the presence of reflectivity patches was unavoidable (Fig.13). The number of pings per line usable for the analysis was about 100 .

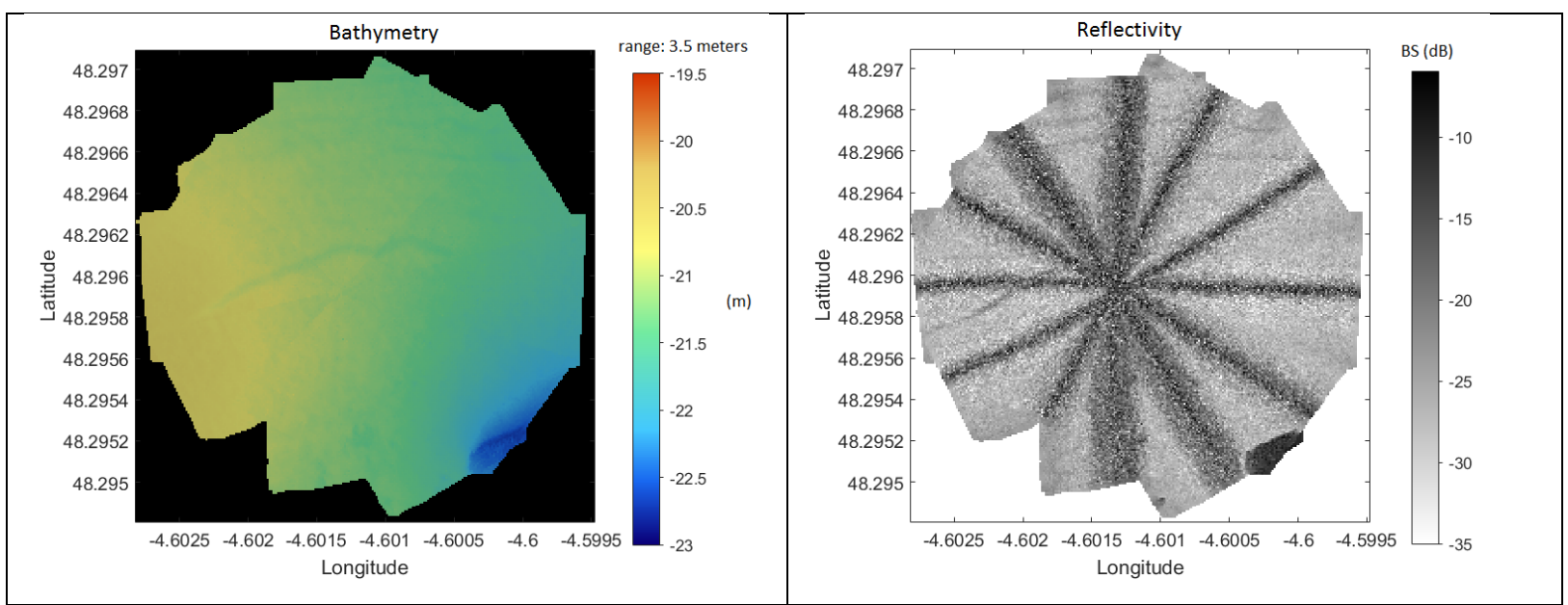

Fig.12. Preliminary configuration data for Camaret\#2 area, June 2016: (left) bathymetry, tide corrected from the Brest tidal station; (right) backscatter level.

For determining the angular backscatter response of the area, $4 \mathrm{WE}$ lines were averaged at $300 \mathrm{kHz}$ and 2 lines at $200 \mathrm{kHz}$. SBES data were collected by EK60 at 10 different tilt angles, covering both sailing directions (WE and EW); the transducer tilt angle shift was estimated to be $4.01^{\circ}$ in the WE direction and $4.04^{\circ}$ in the EW, i.e approximated at $4.0^{\circ}$. The same bottom- 
detection transition angle $\left(20^{\circ}\right)$ as on Carré Renard was used, and one BS value was calculated for each EK60 tilt angle.

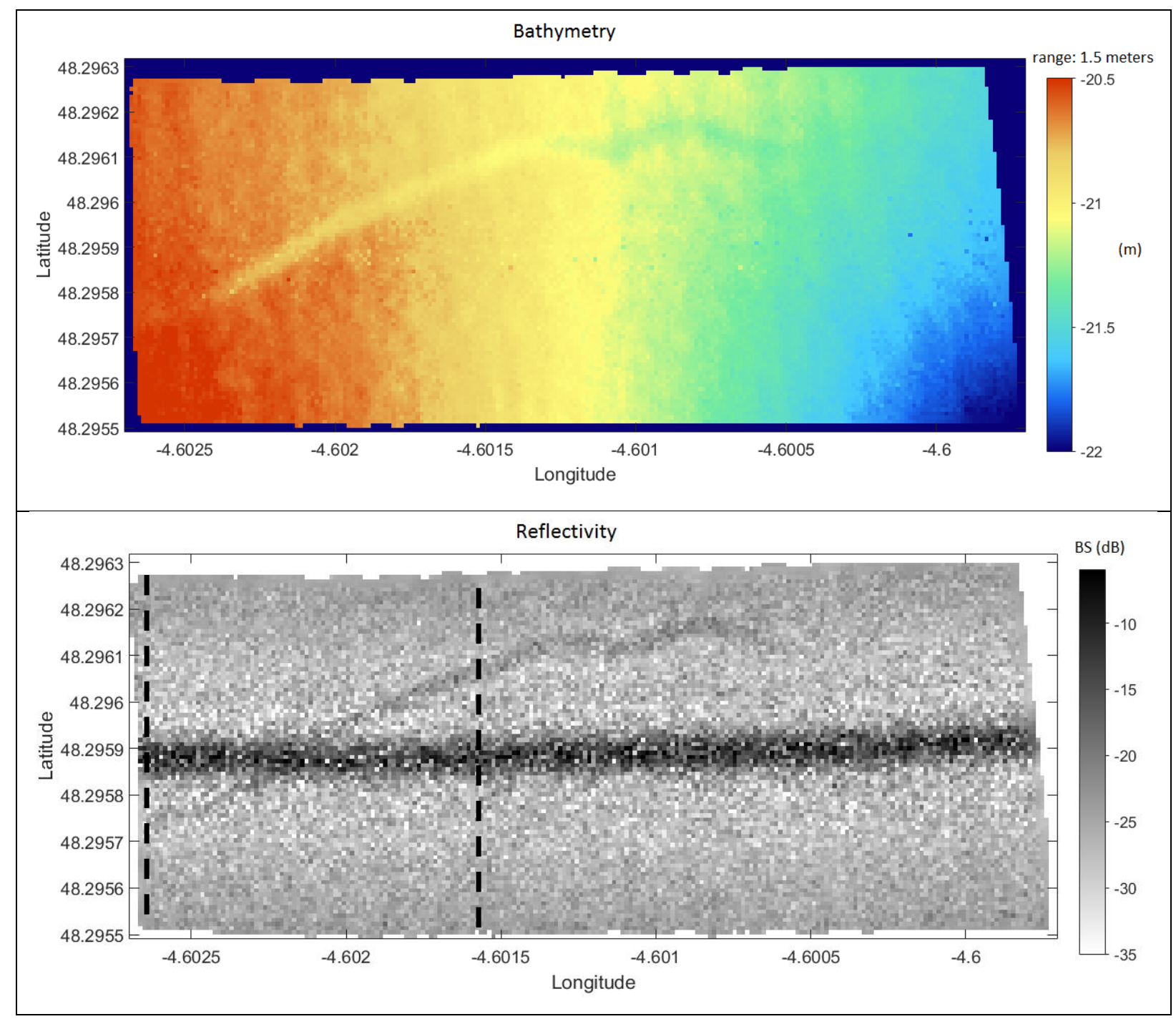

Fig.13. Data for a West-East line on Camaret\#2: (top) bathymetry; (bottom) backscatter at $300 \mathrm{kHz}$. Note an elongated backscatter patch (slightly higher BS values) corresponding to a bathymetry feature (very shallow channel).

Fig. 14 depicts the mean AR logged by EM 2040 at $300 \mathrm{kHz}$ (top) and $200 \mathrm{kHz}$ (bottom). These data were then corrected at both frequencies by the compensation curves determined at Carré Renard (Fig.10 and 11 bottom). Finally, the EM 2040 calibration was validated by comparing these corrected values (blue line) with the corresponding EK60 measurements (green dots) taken on Camaret\#2.

- At $333-300 \mathrm{kHz}$ the average difference is about $1 \mathrm{~dB}$ at all oblique angles (beyond $\pm 10^{\circ}$ ), with systematically higher values at $333 \mathrm{kHz}$. Interestingly this should be put in perspective with the expected frequency dependence of the BS (see Appendix 1): while at Carré Renard this dependence was negligible, on Aulne\#2 a typical 3-dB to 4-dB difference was measured by EK60 at $333 \mathrm{kHz}$ and $200 \mathrm{kHz}$, corresponding to a 0.6- to $0.8-\mathrm{dB}$ difference between $333 \mathrm{kHz}$ and $300 \mathrm{kHz}$; this could explain the 1-dB bias magnitude observed on Fig.13 top. The improvement brought in by the EM 2040 
calibration (see Fig.10 bottom) is very significant.

- At $200 \mathrm{kHz}$, the difference between the two datasets goes from about $1 \mathrm{~dB}$ at steep angles (within $\pm 20^{\circ}$ ) down to $0.5 \mathrm{~dB}$ and less at oblique angles. This is considered as a satisfactory match. The improvement brought in by the EM 2040 calibration (Fig.11 bottom) is clearly more modest that at $300 \mathrm{kHz}$.

This verification has given interesting and positive results, since the test area Camaret\#2 showed a geological facies significantly different from Carré Renard, with backscatter levels lower by $5 \mathrm{~dB}$ (at specular) to $10 \mathrm{~dB}$ (at oblique angles). The consistency of the SBES-MBES difference demonstrates the validity of the method. The results also illustrate the importance of the AR frequency dependence in the interpretation of the results, and emphasize the need for a wide-band analysis of the backscatter AR. Finally, although not reported her, the same validation operation conducted on Aulne\#2 area gave similarly satisfying results over a smaller number of SBES tilt angles.

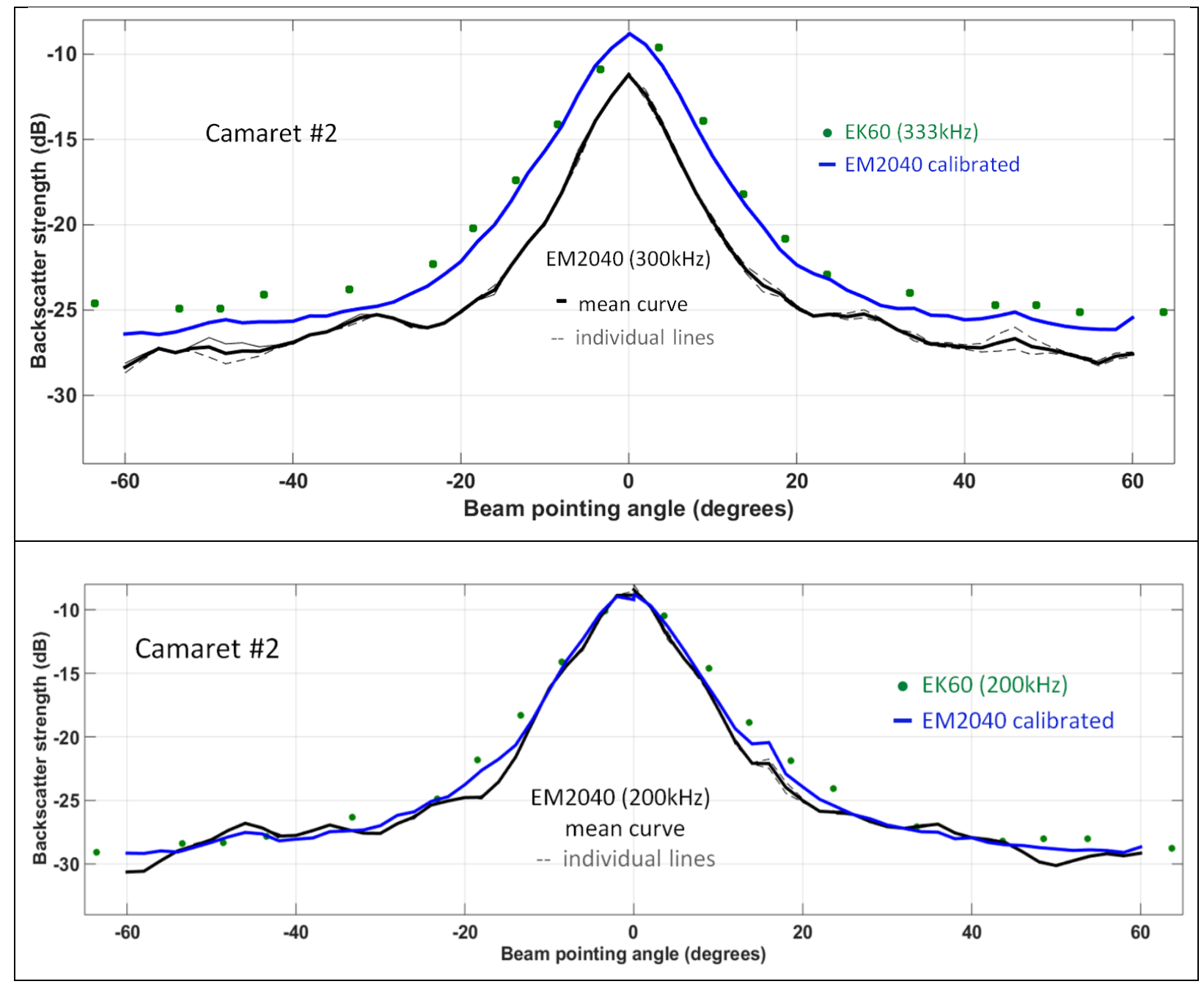

Fig.14. Calibration validation on Camaret\#2 at (top) 333-300 kHz and (bottom) $200 \mathrm{kHz}$. (Solid black) original mean AR of EM 2040; (dashed grey) individual lines from EM 2040; (solid blue) new mean AR from EM 2040 after correction using the compensation curve determined at Carré Renard; (green dots) EK60 values on Camaret\#2. 


\section{Discussion and conclusion}

This article has presented a practical and realistic approach to an important but still unresolved issue: the calibration of MBES for backscatter level absolute measurements. For this purpose we have cross-calibrated a Kongsberg EM 2040 with a calibrated Simrad EK60 using field data recorded on a common natural reference area. The EM 2040 calibration was conducted for two frequencies $200 \mathrm{kHz}$ and $300 \mathrm{kHz}$ while the EK60 was operated at $200 \mathrm{kHz}$ and $333 \mathrm{kHz}$. The estimated average BS difference between 300 and $333 \mathrm{kHz}$ was considered negligible (Appendix 1).

The compensation for signal footprint extent has been done as accurately as possible using precise estimates of the effective pulse length and beam width, and angle values accounting for the sonar motion and the seafloor local topography.

The method was applied to data from the reference area Carré Renard close to the harbour of Brest, France. The cross-calibration procedure was performed on an area (Carré Renard) complying with a number of criteria, the most important ones being planarity, homogeneity and isotropy (Lurton et al. 2017; Roche et al.2018).

On Carré Renard the seafloor angular backscatter was measured with both EM 2040 and EK60. The SBES data were fitted with the GSAB model to get a continuous angular response. The MBES compensation curve (valid for one working mode of the sounder) was computed as the difference between the two datasets. The magnitudes for the compensation were -2 to $+0.5 \mathrm{~dB}$ (at $200 \mathrm{kHz}$ ) and -4 to $-0.5 \mathrm{~dB}$ (at $300 \mathrm{kHz}$ ). These are far from negligible, and $a$ posteriori justifies the efforts required for defining practical calibration procedures and applying them operationally.

To test the validity of this methodology and the success of the calibration, we compared the corrected MBES data (based on the compensation obtained from Carré Renard) on another site (Camaret\#2 with a seafloor angular response clearly differing from Carré Renard while at comparable depths) with independent EK60 calibrated measurements. For most incidence angles and at both operating frequencies, the differences were found within the range 0.5 to $1 \mathrm{~dB}$, hence validating the quality of the EM 2040 calibration procedure. The best agreement was obtained at $200 \mathrm{kHz}$. At $300 \mathrm{kHz}$ a systematic bias was found between the MBES$300 \mathrm{kHz}$ and the SBES-333 kHz; this was interpreted by the frequency dependence observed on Camaret\#2, less favourable than observed on Carré Renard. For completeness of the verification, such a checking should also be conducted on areas with significantly different water depths, which was not possible given the constraints of our cruises in the Bay of Brest. We note that the incident angle accurate determination is hampered by the characteristics of the mechanical deployment device used to tilt the SBES transducer, making delicate the determination of a correct vertical reference - with a bigger impact at steep angles where the $\mathrm{BS}$ variation with angle is faster.

A key point for the validity and the generality of the method is the application of accurate estimates of the signal footprint extent on the seafloor. For SBES, the availability of beam patterns measured by the manufacturer and the relatively simple footprint geometry give a good confidence in the model approximations used for the reference data processing. Comparatively, the system configuration and geometry for MBES using Mill's cross transducers is significantly more complicated, and may lead to bias the backscatter estimation, especially around normal incidence where the footprint area is a complex combination of beam directivity and pulse envelope shape. This bias is de facto compensated for by the calibration method proposed here. However, in the absence of a fully reliable ensonified area model, this compensation will be accurate only at the depth of the calibration area and for the 
same pulse length; otherwise the model inaccuracy will lead to imperfect results of the compensation. Hence an important objective for the immediate future is to develop and apply more accurate expressions for the footprint extent (ideally through analytical developments, otherwise using numerical simulations), and on the experimental side to acquire and process backscatter data from SBES and MBES in the same cross-calibration framework over an increased range of water depths.

A method improvement could be a real-time compensation of the SBES motion through the Pan \& Tilt system; with such a compensation, the data quality would be less sensitive to the sonar motion. Another coming improvement is to use as reference SBES the new wide-band Simrad EK80 (Demer et al 2017) which makes it possible to vary the working frequency to exactly match the MBES signals whose frequency varies with the system's settings.

Ideally, it would be preferable that MBES field-calibration routine operations are conducted on reference natural areas with a fully-controlled backscatter level. Unfortunately, the criteria that such reference areas have to satisfy are multiple and demanding, and in real environments it is actually very difficult to identify such a perfect configuration. Moreover, it is often desirable that the calibration can be operated in a non-prepared environment - similarly to the opportunistic "patch-test" commonly conducted in bathymetry. In this respect the MBES cross-calibration with a SBES shows serious advantages, since it avoids the need for a perfectly controlled permanent reference area; however the identification of an opportunistic area suitable for such comparative measurements must also fulfil several requirements. Nevertheless, in our work we demonstrated that even in areas already known as problematic (such as Camaret\#2) a thorough investigation of their characteristics can assist in identifying at least one line that can be usable for the calibration procedure.

The principle of the cross-calibration method presented above is simple and straightforward. Its practical application implies the operation of a calibrated SBES deployed on a Pan \& Tilt system; although cumbersome, this is practically very feasible. For future cross-calibration of medium-frequency MBES class (around $100 \mathrm{kHz}$ ), the extension of the method down to a lower frequency range (using 70 and/or $120 \mathrm{kHz}$ SBES) should raise no particular feasibility issue. The application to lower frequencies (down to 30 and $12 \mathrm{kHz}$ ) implying bigger and heavier transducers is expected to be more problematic and may show one practical limit of the method; however recent results (Ladroit et al. 2017) obtained at $38 \mathrm{kHz}$ and a $45^{\circ}$ tilt proved the feasibility of the method even in this frequency range.

The approach of MBES field-calibration presented here could, in the longer term, be practically combined with the now-classical bathymetric calibration operation and potentially become a standard procedure for ensuring routine acquisition of accurate backscatter measurements by MBES.

Finally, whatever the backscatter calibration method, the resulting compensation parameters should be ideally taken into account by the echosounders for directly correcting the measured reflectivity data; or at least should be made usable in MBES-dedicated software suites for application in post-processing operations. Unfortunately, none of these possibilities is fully available today; it is expected from sonar manufacturers and software developers that they bring such improvements to their products in a near future. 


\section{Acknowledgements}

The post-doc position of Dimitrios Eleftherakis at Ifremer was funded by SHOM (Service Hydrographique et Océanographique de la Marine, France) under contract 14CR02. The study was conducted in the framework of the Ifremer R\&D project R403-006 "Underwater Acoustics". We especially thank SHOM for co-funding the various recent and on-going projects aimed at identifying reference areas close to Brest harbour and defining a methodology for MBES absolute calibration; more specifically we would like to thank Christophe Vrignaud and Sophie Loyer for their constant support and useful discussions along the project. We gratefully acknowledge our Ifremer/Dyneco colleagues Xavier Caisey and Jean-Dominique Gaffet for their help in collecting videos and grab samples, and the captain and crew of RV Thalia for their invaluable role in the success of the numerous survey cruises.

\section{Appendix 1: BS difference assessment between $333 \mathrm{kHz}$ and $300 \mathrm{kHz}$}

This section attempts to assess whether the SBES reflectivity measured at $333 \mathrm{kHz}$ can be used as a reference for the nominal MBES frequency of $300 \mathrm{kHz}$. For this purpose, the SBES data measured on Carré Renard at both 200 and $333 \mathrm{kHz}$ under the same conditions (Fig.10 and Fig.11) are plotted together in Fig.A1 (green curves), after fitting the GSAB model. Comparison of the levels at the two frequencies shows a difference less than $1 \mathrm{~dB}$ - an average magnitude of $0.6 \mathrm{~dB}$ is retained. For a 1-dB difference, and assuming a logarithmic dependence of backscatter level with frequency (Weber and Ward 2015), the magnitude of the BS deviation between 300 and $333 \mathrm{kHz}$ can be estimated as:

$$
\mathrm{BS}_{333}-\mathrm{BS}_{300}=\log (333 / 300) / \log (333 / 200) \approx 0.21 \mathrm{~dB}
$$

This discrepancy is not considered to be really penalizing given the inaccuracies observable elsewhere; therefore it will be admitted that the backscatter levels measured at Carré Renard at 300 and $333 \mathrm{kHz}$ are not significantly different, and hence the cross-calibration between the $300-\mathrm{kHz}$ MBES and the 333-kHz SBES is acceptably accurate with respect to this frequency approximation.

Interestingly, the same exercise done with the data from Aulne\#2 (black) and Camaret\#2 (red) does not show the same trend. While the frequency dependence remains negligible in the specular lobe, it increases significantly at oblique incidences and reaches $2.5 \mathrm{~dB}$ at $60^{\circ}$ for Aulne\#2, and $4 \mathrm{~dB}$ for Camaret\#2. Using the same frequency-dependence model as above, the $300-333 \mathrm{kHz}$ differential reaches $0.4,0.6$ and $0.8 \mathrm{~dB}$ for a $200-333 \mathrm{kHz}$ differential of respectively 2,3 and $4 \mathrm{~dB}$. 


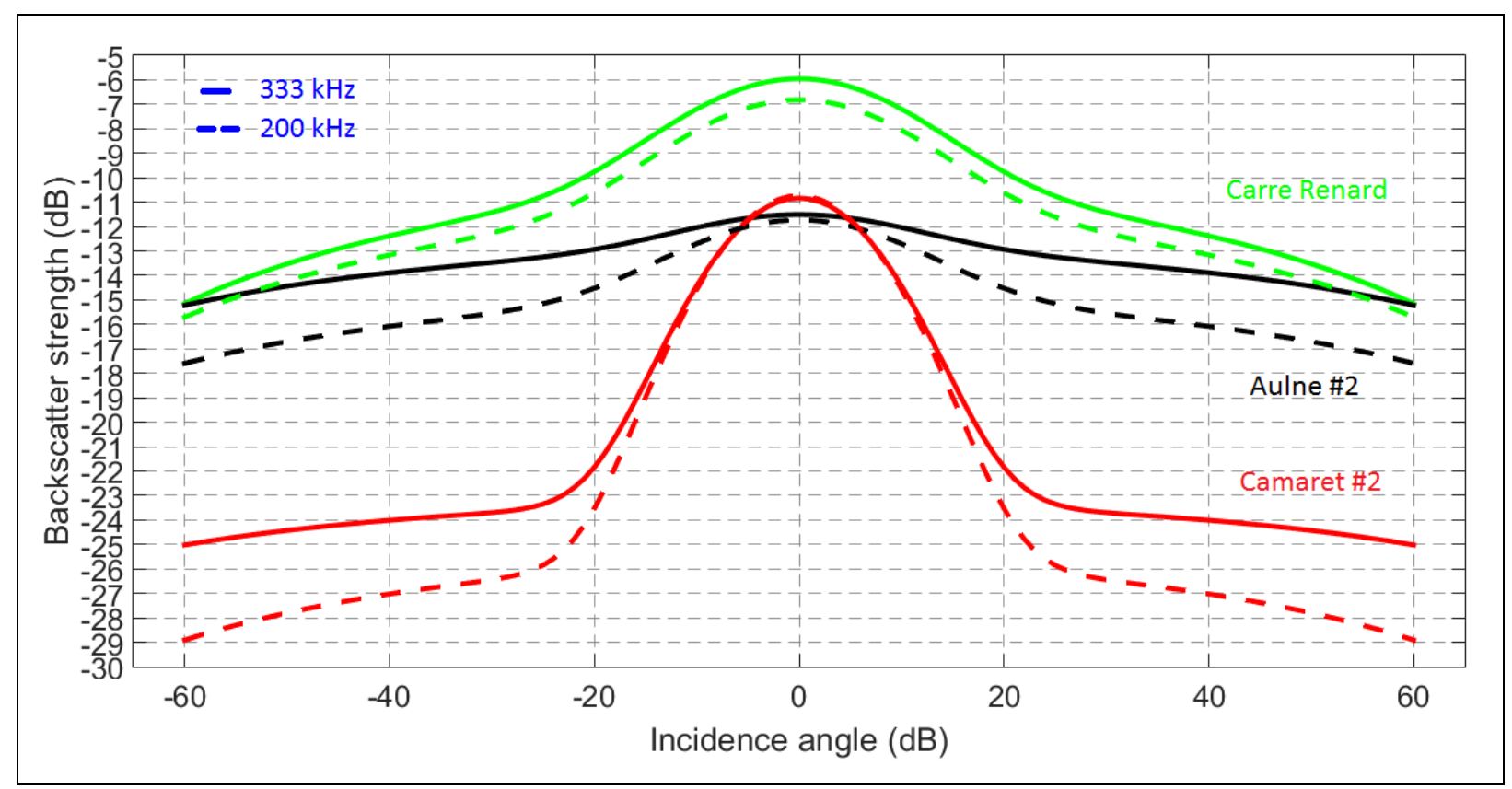

Fig.A1 Frequency dependence of the backscatter level AR measured on three different areas. The calibrated EK60 results were measured at $333 \mathrm{kHz}$ (solid) and $200 \mathrm{kHz}$ (dashed) at Carré Renard (green), Aulne\#2 (black) and Camaret\#2 (red).

\section{REFERENCES}

Amiri-Simkooei AR, Snellen M, Simons DG (2009). Riverbed sediment classification using multi-beam echosounder, . J. Acoust. Soc. Am. vol. 126 (4), pp 1724-1738, DOI: 10.1121/1.3205397

APL-UW high-frequency ocean environmental acoustic models handbook. (1994). Technical report APL-UW TR9407AEAS9501, Applied Physics Laboratory, University of Washington, pp. IV1-IV50.

Augustin JM (2016) SonarScope ${ }^{\circledR}$ software on-line presentation. http://flotte.ifremer.fr/fleet/Presentation-of-thefleet/On-board-software/SonarScope

Bodholt H (2002) The effect of water temperature and salinity on echosounder measurements. ICES Symposium on Acoustics in Fisheries. Montpellier, France June 2002, presentation \#123.

Brown C, Schmidt V, Malik M, Le Bouffant N (2015) Chapter 4 - Backscatter measurement by bathymetric echo sounders. In: Lurton $X$ and Lamarche $G$ (Eds). Backscatter measurements by seafloor-mapping sonars Guidelines and Recommendations. Geohab Report, 79-106 - http://geohab.org/publications/

Brown C. J., Smith S. J., Lawton P., and Anderson J.T. (2011). Benthic habitat mapping: A review of progress towards improved understanding of the spatial ecology of the seafloor using acoustic techniques. Estuarine Coastal Shelf Sci. 92, 502-520

Buscombe, D., Grams, P.E., Kaplinski, M.A. (2014), Characterizing riverbed sediment using high-frequency acoustics 1: Spectral properties of scattering. Journal of Geophysical Research-Earth Surface 119, doi:10.1002/2014 JF003189.

Canepa G, Pouliquen E (2005) Inversion of geo-acoustic properties from high frequency multibeam data. in: Boundary influences in high frequency, shallow water acoustics. Pace NG and Blondel P (Eds.), Bath UK, pp 233-240

Demer DA, Berger L., Bernasconi M, Bethke E, Boswell K, Chu D, Domokos R, et al. (2015) Calibration of acoustic instruments. ICES Cooperative Research Report No. 326, p. 130

Demer DA, Andersen LN, Bassett C, Berger L, Chu D, Condiotty J, Cutter Jr G, Hutton B, Korneliussen RJ, Le 
Bouffant N, Macaulay GJ, Michaels WL, Murfin D, Pobitzer A, Renfree JS, Sessions TS, Stierhoff KL, Thompson C (2017). USA Norway EK80 Workshop Report: Evaluation of a wideband echosounder for fisheries and marine ecosystem science. ICES Cooperative Research Report 336, ICES publishing, NOAA's Southwest Fisheries Science Center in San Diego, California, USA. DOI: 10.17895/ices.pub.2318.

Cochrane NA, Li Y, Melvin GD (2003) Quantification of a multibeam sonar for fisheries assessment applications. J. Acoust. Soc. Am. 114, pp 745-758.

De Moustier C (1986) Beyond bathymetry: Mapping acoustic backscattering from the deep seafloor with Sea Beam. J. Acoust. Soc. Am. vol. 79 (2), pp 316-331

Diesing M, Mitchell P, Stephens D (2016) Image-based seabed classification: what can we learn from terrestrial remote sensing? ICES Journal of Marine Science, 73, pp 2425-2441

Eleftherakis D, Amiri-Simkooei A, Snellen M, and Simons DG (2012) Improving riverbed sediment classification using backscatter and depth residual features of multi-beam echo-sounder systems, J. Acoust. Soc. Am. 131(5), 3710-3725

Eleftherakis D, Snellen M, Amiri-Simkooei A, Simons DG, Siemes K (2014) Observations regarding coarse sediment classification based on multi-beam echo-sounder's backscatter strength and depth residuals in Dutch rivers. J Acoust Soc Am 135(6), 3305-3315

Fonseca L, Mayer L (2007) Remote estimation of surficial seafloor properties through the application Angular Range Analysis to multibeam sonar data. Marine Geophysical Researches, 28, pp 119-126

Foote KG, Chu D, Hammar TR, Baldwin KC, Mayer LA, Hufnagle LCJr, Jech JM (2005) Protocols for calibrating multibeam sonar. J. Acoust. Soc. Am., 117, pp 2013-2027

Gaunaurd, GC,Überall H (1983). RST analysis of monostatic and bistatic acoustic echoes from an elastic sphere. J. Acoust. Soc. America, Volume 73, pp. 1-12

Gutierrez FJ, Manley-Cooke P, Tamset D (2016) Calibrated Acoustic Backscatter from a Phase-Measuring Bathymetric Sonar. Geohab 2016, Winchester, UK, 2-6 May 2016

Hammerstad E. (2000) Backscattering and Seabed Image Reflectivity. EM Technical Note, http://www.km.kongsberg.com/ks/web/nokbg0397.nsf/AllWeb/226C1AFA658B1343C1256D4E002EC764/\$file/ EM_technical_note_web_BackscatteringSeabedImageReflectivity.pdf

Hellequin L, Boucher JM, and Lurton X (2003) Processing of high-frequency multibeam echo sounder data for seafloor characterization. IEEE Journal of Oceanic Engineering 28(1), pp 78-89

Hughes Clarke JE (1994) Toward remote seafloor classification using the angular response of acoustic backscattering: a case study from multiple overlapping GLORIA data. IEEE Journal of Oceanic Engineering 19(1), pp 112-126

International Hydrographic Bureau Monaco (2008). IHO Standards for hydrographic surveys, 5th Edition, February 2008 Special Publication No. 44.

Kongsberg (2011) Kongsberg EM 2040 Multibeam Echo Sounder - Instruction Manual. Kongsberg Maritime AS. Document 346210/B

Ladroit Y, Lamarche G, Pallentin A (2017) Seafloor multibeam backscatter calibration experiment - Comparing 45 degrees-tilted $38 \mathrm{kHz}$ split-beam echosounder and $30 \mathrm{kHz}$ multibeam data, in Lamarche $\mathrm{G}$ and Lurton $\mathrm{X}$ (Eds) Marine Geophysical Research, Seafloor backscatter data from swath mapping echosounders: From technological development to novel applications doi: https://doi.org/10.1007/s11001-017-9340-5

Lamarche G., Lurton X., Augustin J.-M., Verdier A.-L. (2011) Quantitative characterization of seafloor substrate and bedforms using advanced processing of multibeam backscatter. Application to the Cook Strait, New Zealand. Continental Shelf Research, vol.31, pp 93-109

Lamarche G, Lurton X (2017) Recommendations for improved and coherent acquisition and processing of backscatter data from seafloor-mapping sonars. In: Lamarche $G$ and Lurton X (Eds) Marine Geophysical Research, Seafloor backscatter data from swath mapping echosounders: From technological development to novel applications. DOI 10.1007/s11001-017-9315-6

Lanzoni C, Weber, TC (2010). High-resolution calibration of a multibeam echo sounder. IEEE Oceans' 2010

Lanzoni C, Weber TC (2012) Calibration of multibeam echosounders : a comparison between two methodologies. 11th European Conference on Underwater Acoustics, Edinburgh, Scotland, July 2-6 
Long DG, Skouson GB (1995) Calibration of Spaceborne Scatterometers using Tropical Rainforests. IEEE Trans Geoscience and Remote Sensing, 34 (2), pp 413-424

Lurton X (2010) An Introduction to underwater acoustics: principles and applications $-2^{\text {nd }}$ Edition. Springer, Berlin

Lurton X, Le Bouffant N, Mopin I (2013) Intensity calibration of Multibeam Echosounders. Kongsberg Users Forum Femme'2013, Boston

Lurton X, Lamarche G (Eds) (2015) Backscatter measurements by seafloor mapping sonars. Guidelines and Recommendations. Geohab Report, 200 pp, http://geohab.org/publications/

Lurton X, Eleftherakis D, Augustin JM (2017) Analysis of seafloor backscatter strength dependence on the azimuthal angle using multibeam echosounder data. In: Lamarche G and Lurton X (Eds) Marine Geophysical Research, Seafloor backscatter data from swath mapping echosounders: From technological development to novel applications: DOI 10.1007/s11001-017-9318-3.

Malik M, Lurton X, Mayer L (2018) A Framework to quantify uncertainties of seafloor backscatter from swath mapping echosounders. In: Lamarche G and Lurton X (Eds) Marine Geophysical Research, Seafloor backscatter data from swath mapping echosounders: From technological development to novel applications.

Ona E, Mazauric V, Andersen LN (2009) Calibration methods for two scientific multibeam systems. ICES J. Mar. Sci. 66, pp 1326-1334.

Perrot Y, Brehmer P, Roudaut G, Gerstoft P, Josse E (2014) Efficient multibeam sonar calibration and performance evaluation. Int. J. Eng. Sci. Innov. Technol. 3, pp 808-820.

Preston J (2009) Automated acoustic seabed classification of multibeam images of Stanton Banks. Applied Acoustics, 70, pp $1277-1287$.

Rice G, Cooper R, Degrendele K, Gutierrez F, Le Bouffant N, Roche M (2015) Chapter 5 - Acquisition: best practice guide. In: Lurton, X., and Lamarche, G. (Eds). Backscatter measurements by seafloor-mapping sonars Guidelines and Recommendations. Geohab report, 106-132 - http://geohab.org/publications/

Roche M, Degrendele K, Vrignaud C, Loyer S, Le Bas T, Augustin JM, Lurton X (2018) Control of the repeatability of high frequency multibeam echosounder backscatter by using reference areas. In: Lamarche $\mathrm{G}$ and Lurton X (Eds) Marine Geophysical Research, Seafloor backscatter data from swath mapping echosounders: From technological development to novel applications. https://doi.org/10.1007/s11001-018-9343-X

Simmonds JE, MacLennan DN (2005) Fisheries Acoustics: Theory and Practice. Wiley-Blackwell, Oxford, $456 \mathrm{pp}$

Simons DG, Snellen M (2009) A Bayesian approach to seafloor classification using multi-beam echo-sounder backscatter data. Applied Acoustics, vol.70, pp 1258-1268

Snellen M, Eleftherakis D, Amiri-Simkooei A, Koomans R, Simons DG (2013) An inter-comparison of sediment classification methods based on multi-beam echo-sounder backscatter data and sediment natural radio-activity, Journal of the Acoustical Society of America, 134(2), pp 959-970

Weber TC, Ward LG (2015) Observations of Backscatter from Sand and Gravel Seafloors between 170 and 250 kHz. J.Acoust.Soc.Am. vol.138(4), pp 2169-2180

Weber, T., Rice, G. and Smith, M. (2017) Toward a standard line for use in mutlibeam echo sounder calibration, in Lamarche, G., and Lurton, X. (Eds) Seafloor backscatter data from swath mapping echosounders: From technological development to novel applications Marine Geophysical Research, 1-13. https://doi.org/10.1007/s11001-017-9334-3

Wendelboe G, Barchard S, Maillard E, Bjørnø L (2010) Towards a Fully Calibrated Multibeam Echosounder, J. Acoust. Soc. Am. 128, 2383 
Click here to download Figure Figure 1.tif $\underline{\underline{ }}$

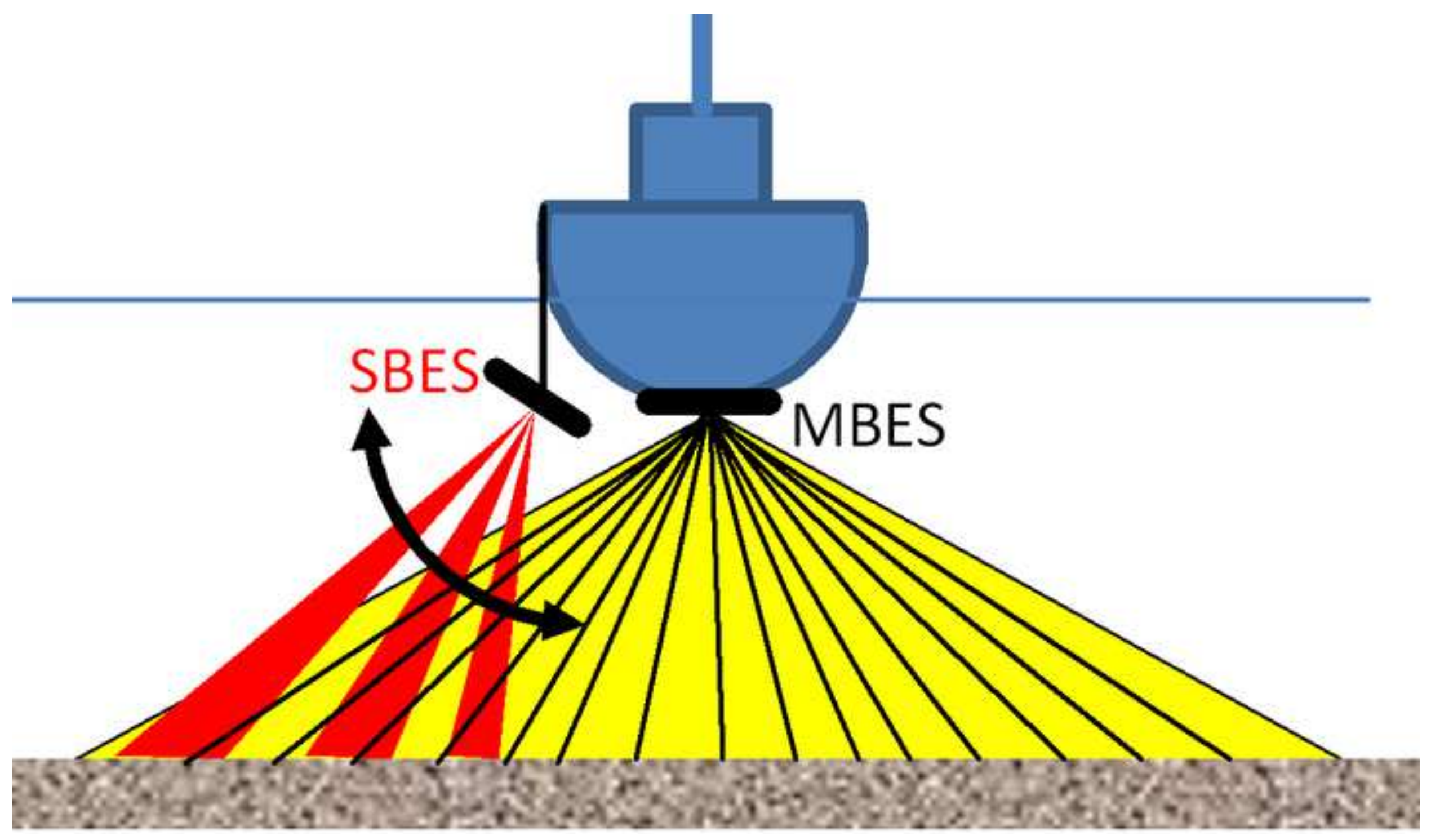




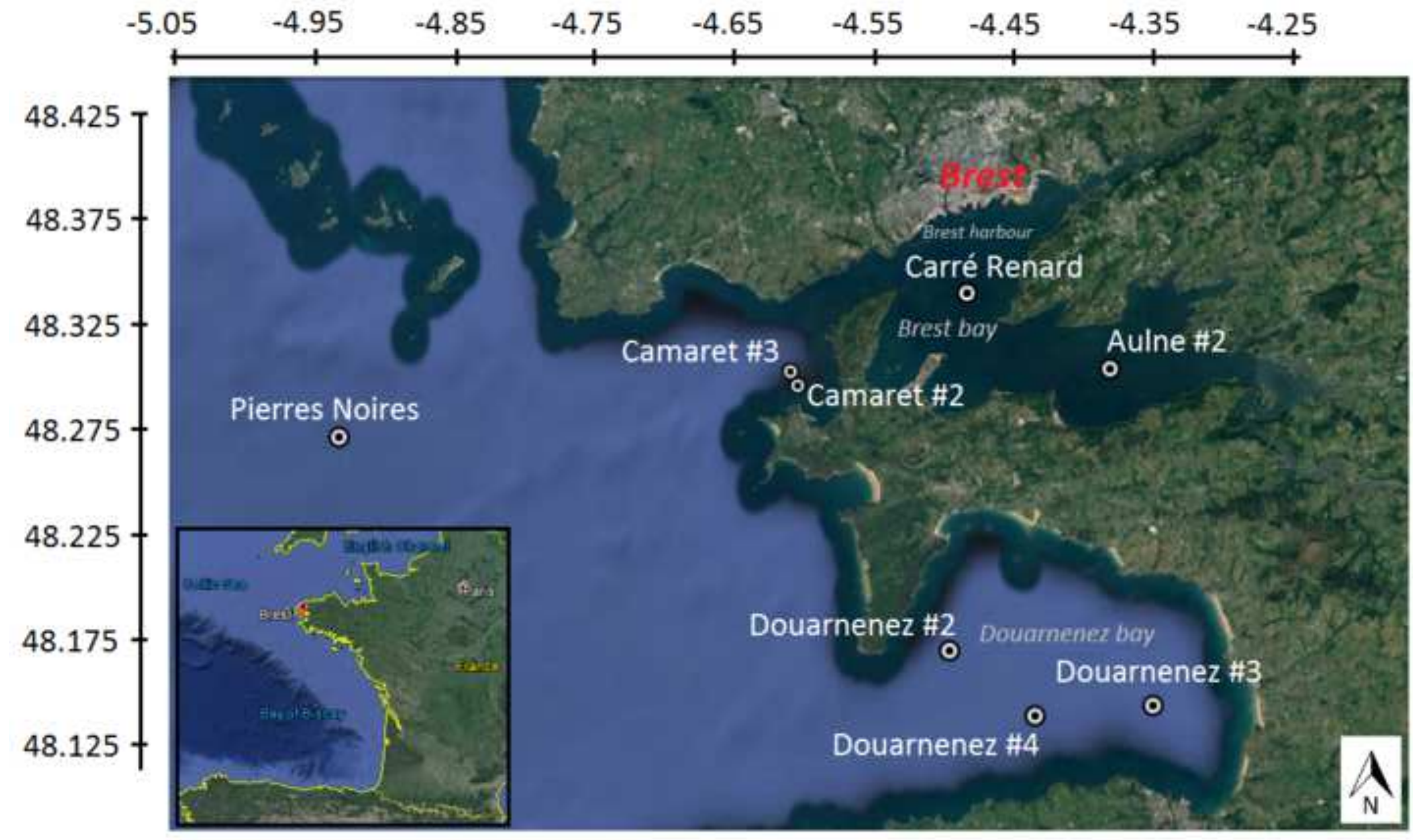


Click here to download Figure Figure 3.tif $\underline{\underline{\underline{ }}}$

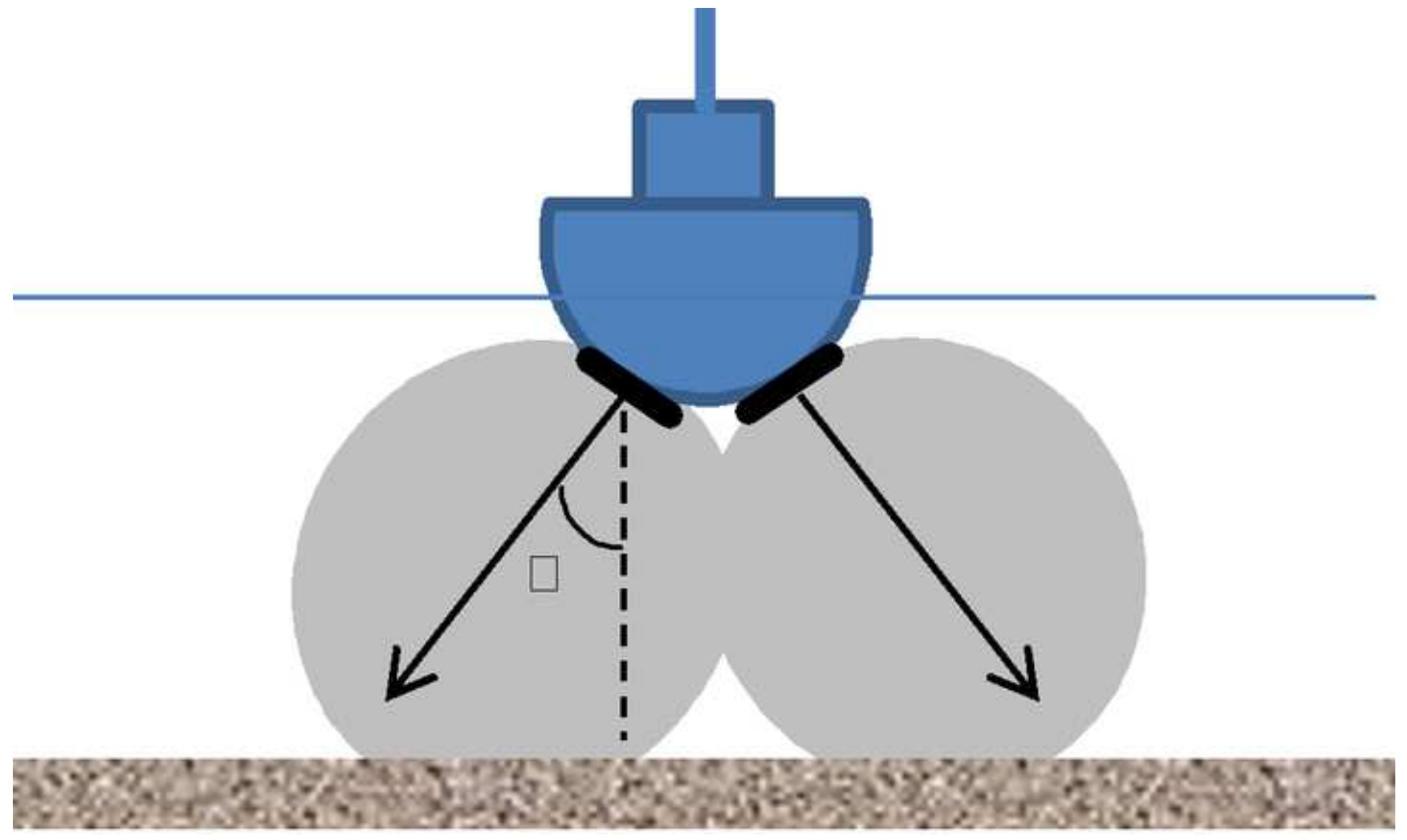




\section{SBES transducers}

\section{Pole tip}

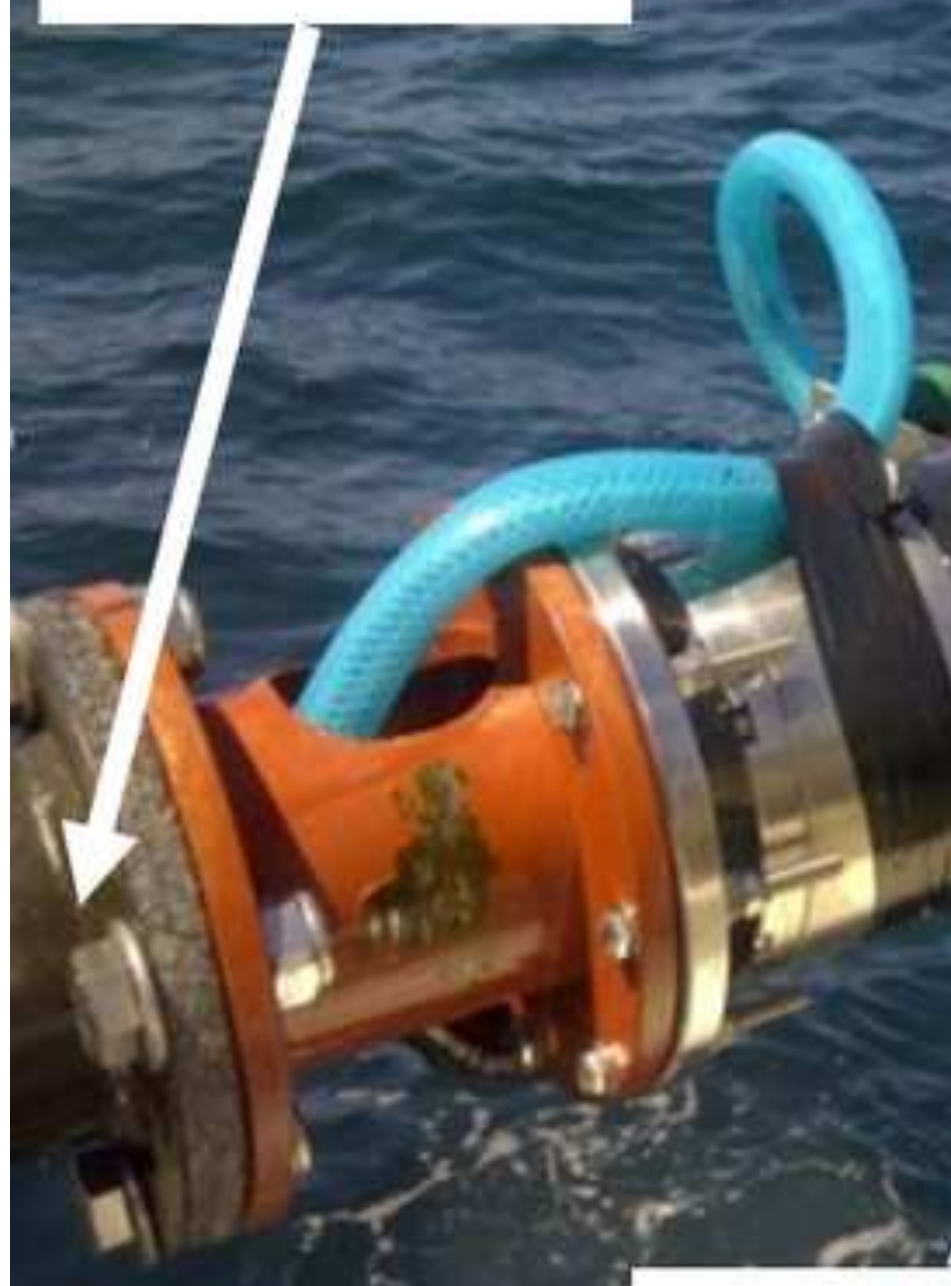

Pan \& Tilt 
Click here to download Figure Figure 5.tif $\underline{\underline{\boldsymbol{}}}$
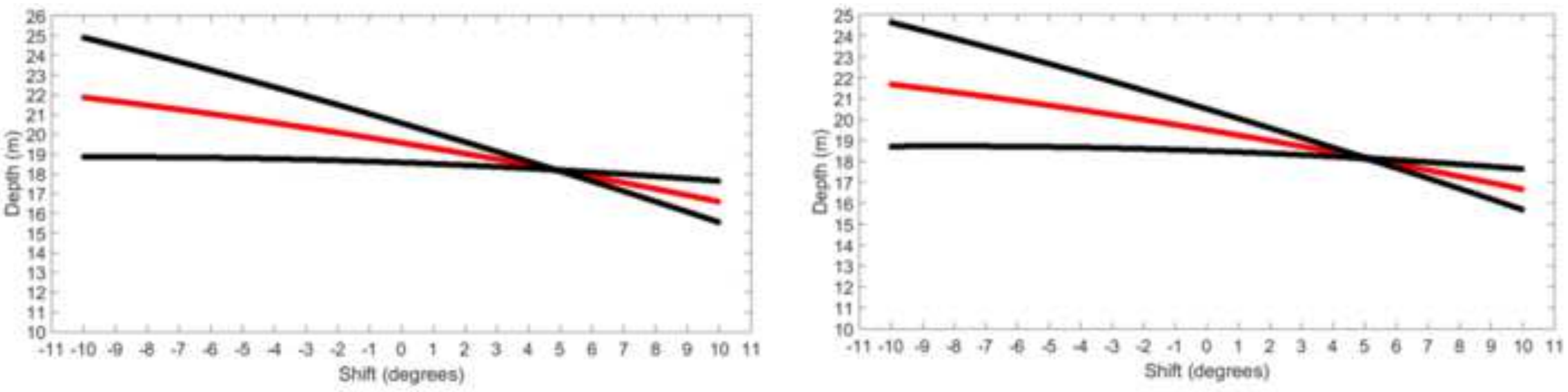

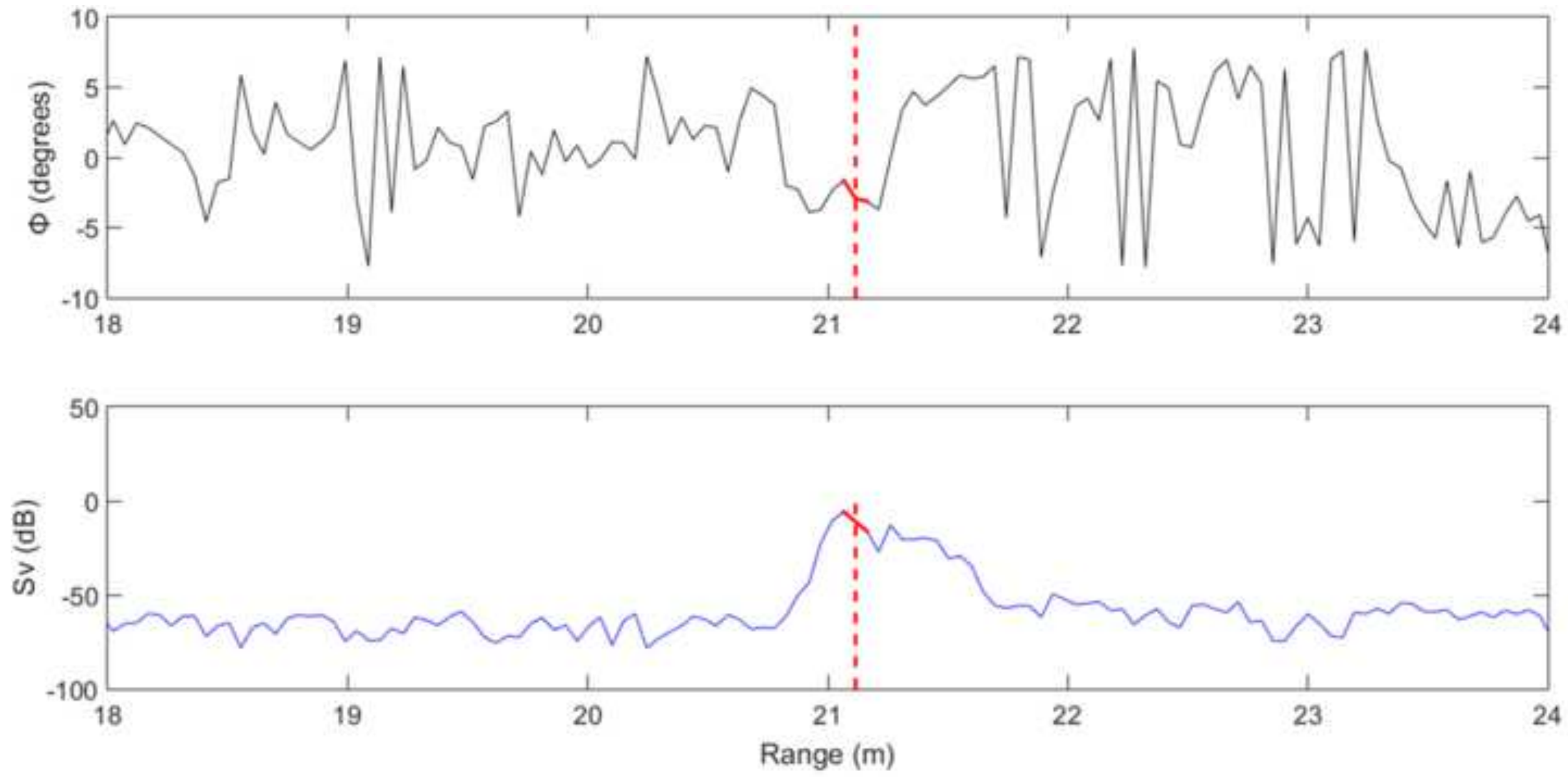

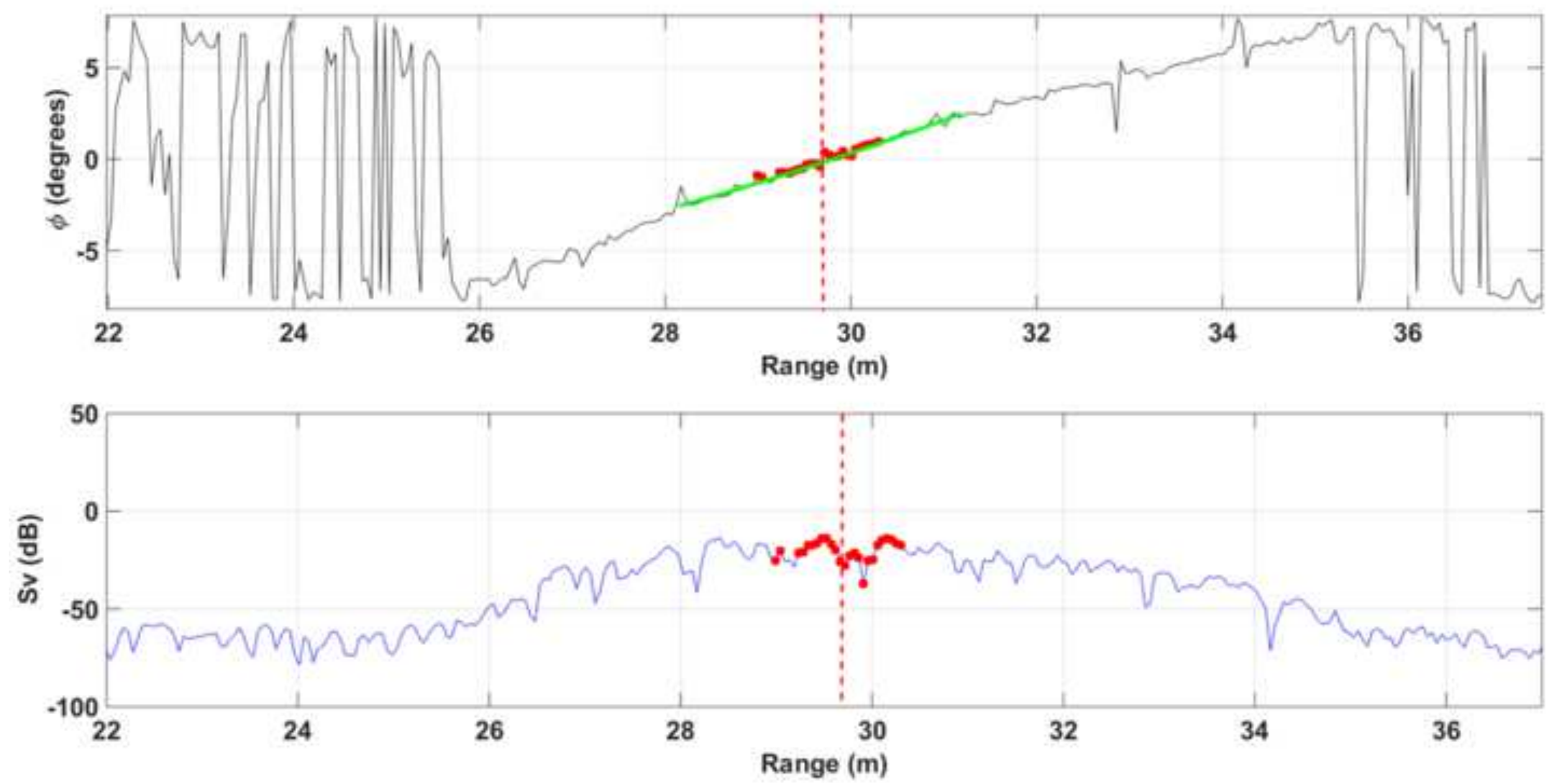


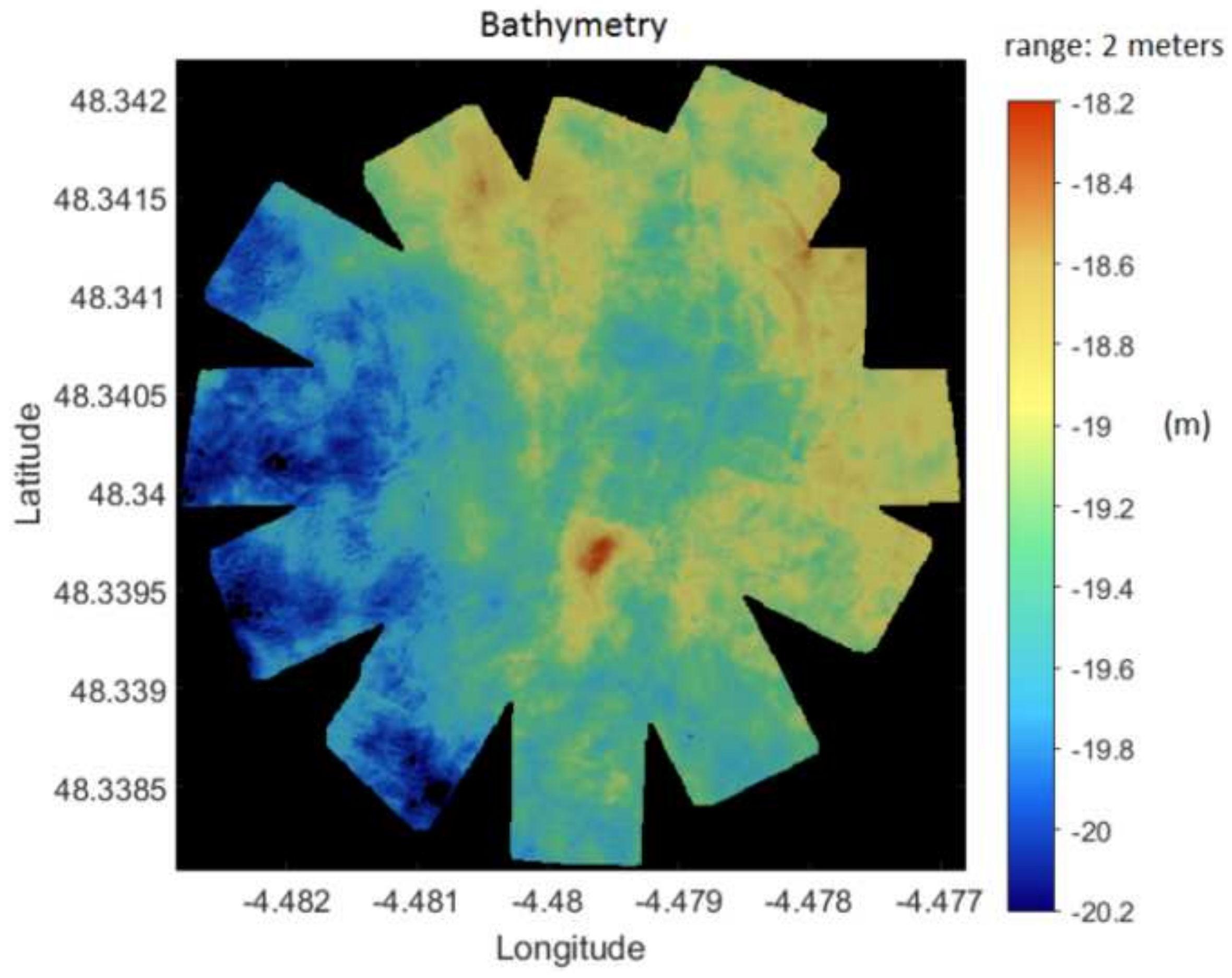




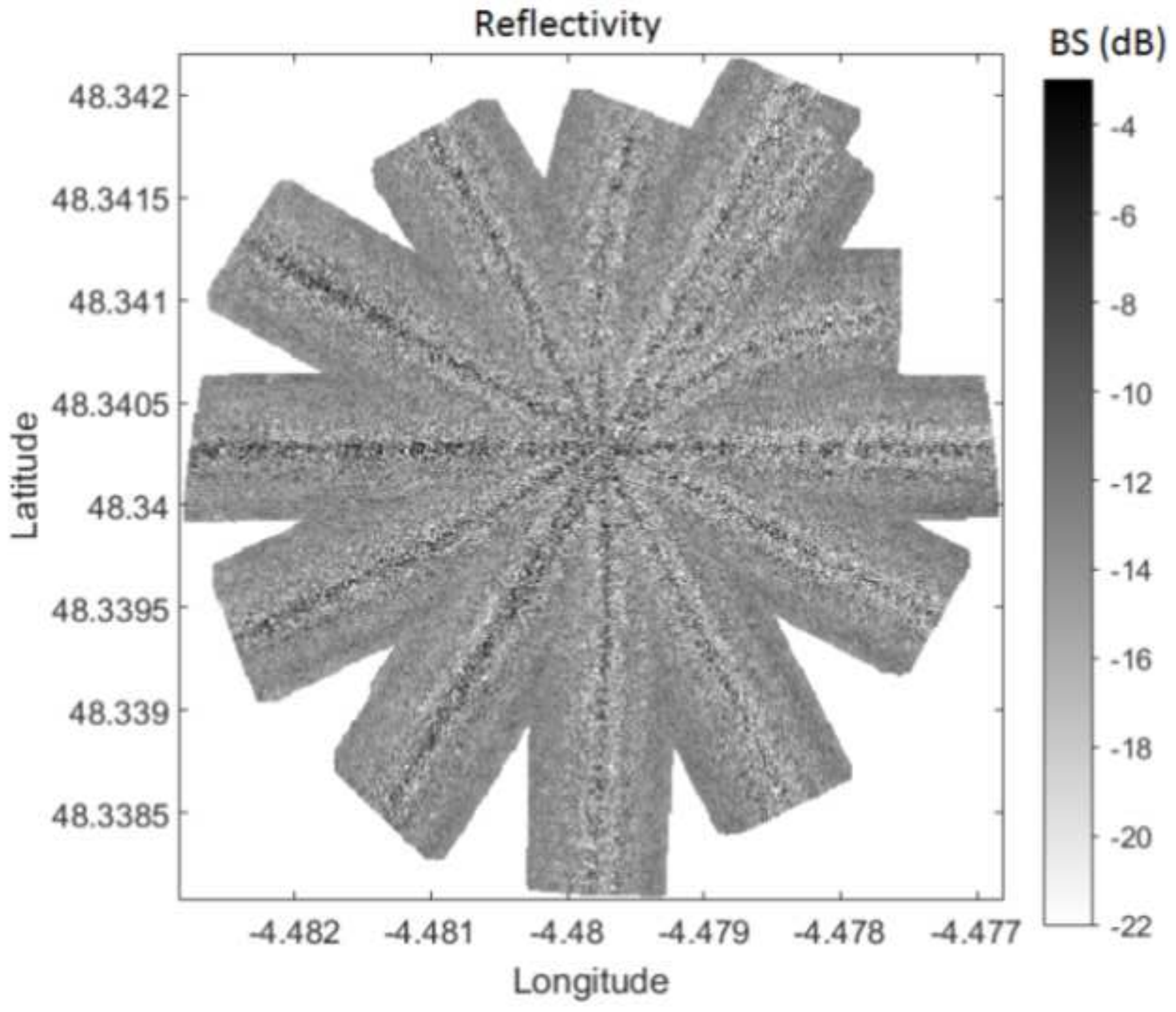




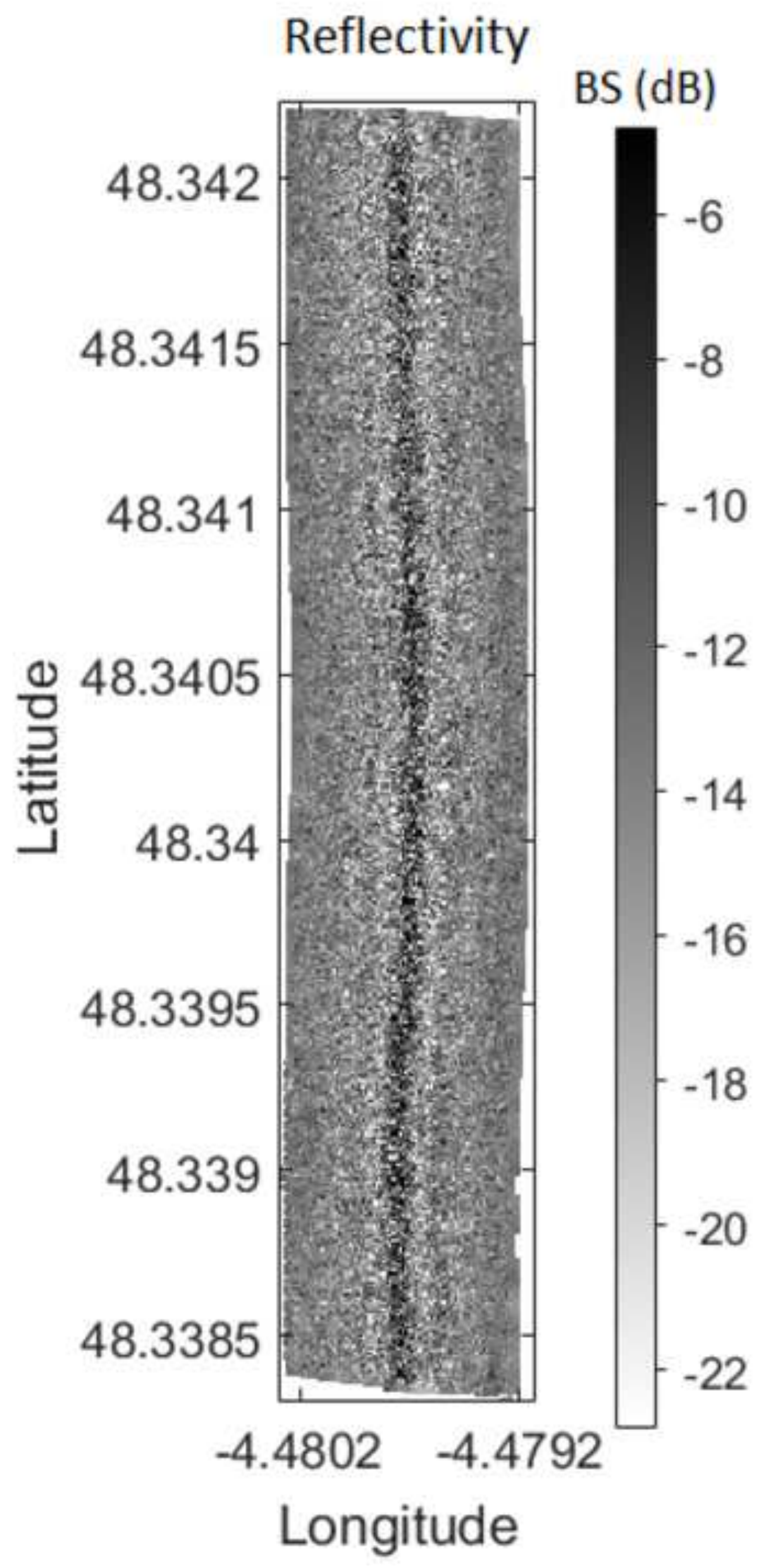




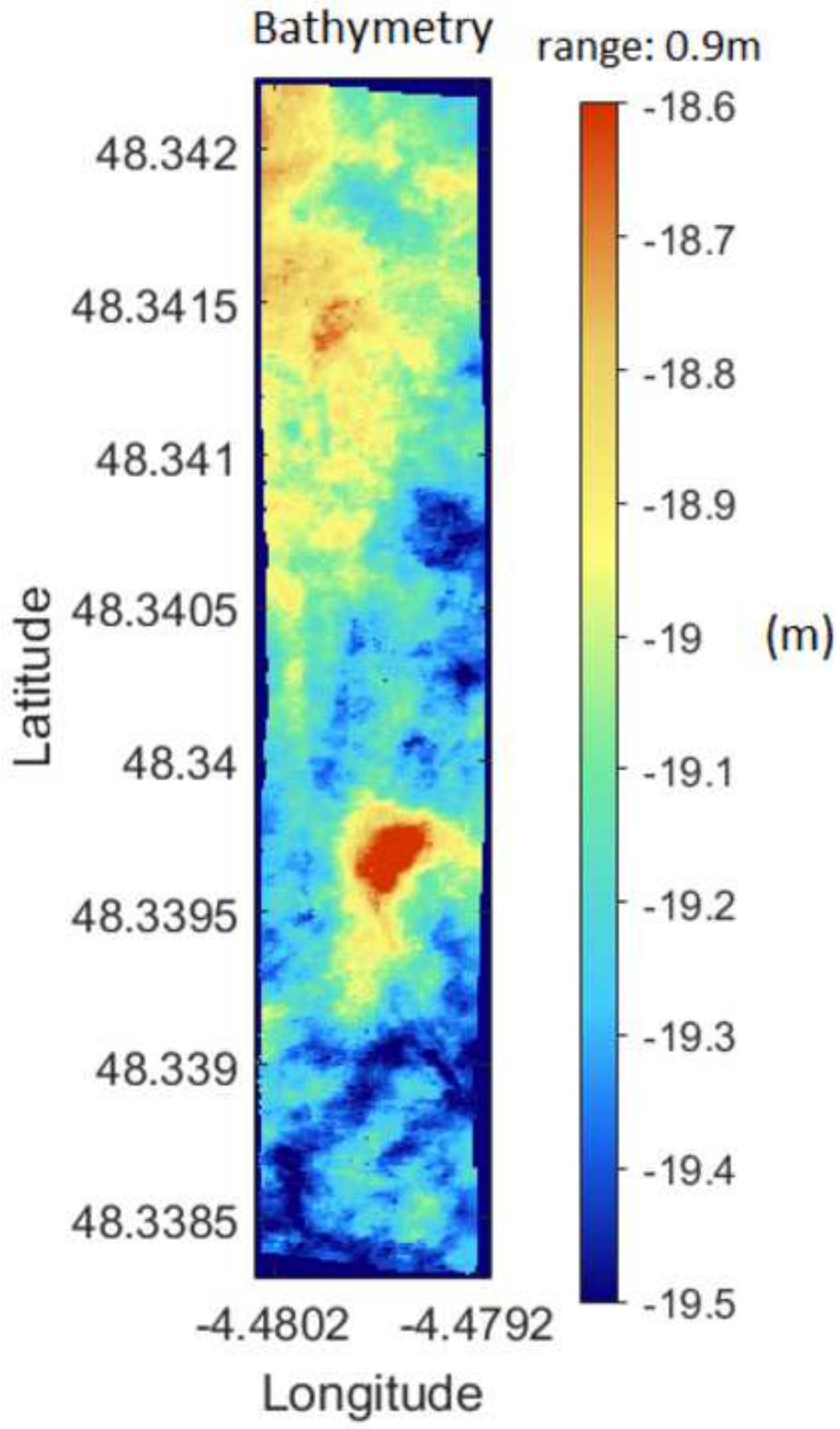




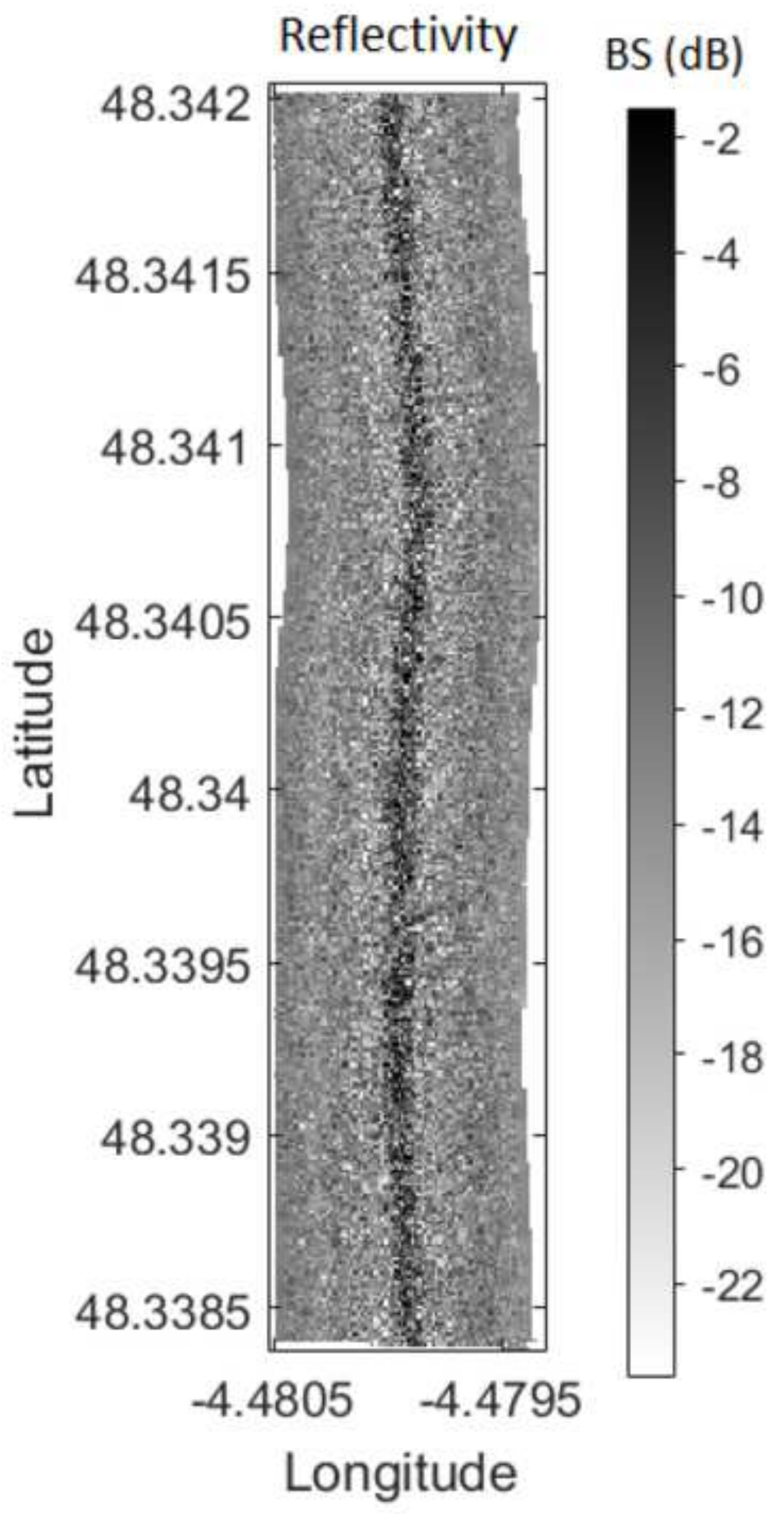




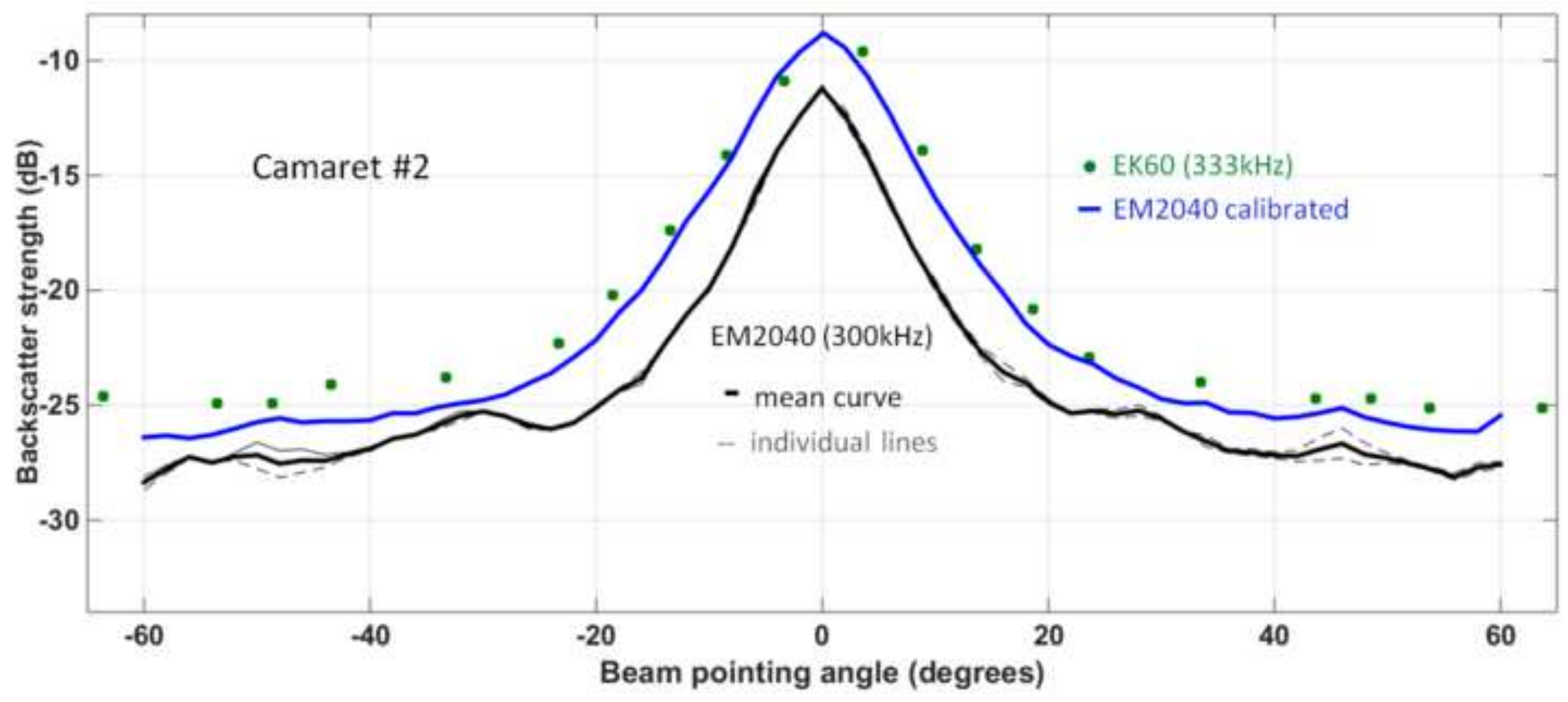


Click here to download Figure Figure 11.PNG $\underline{\underline{ }}$

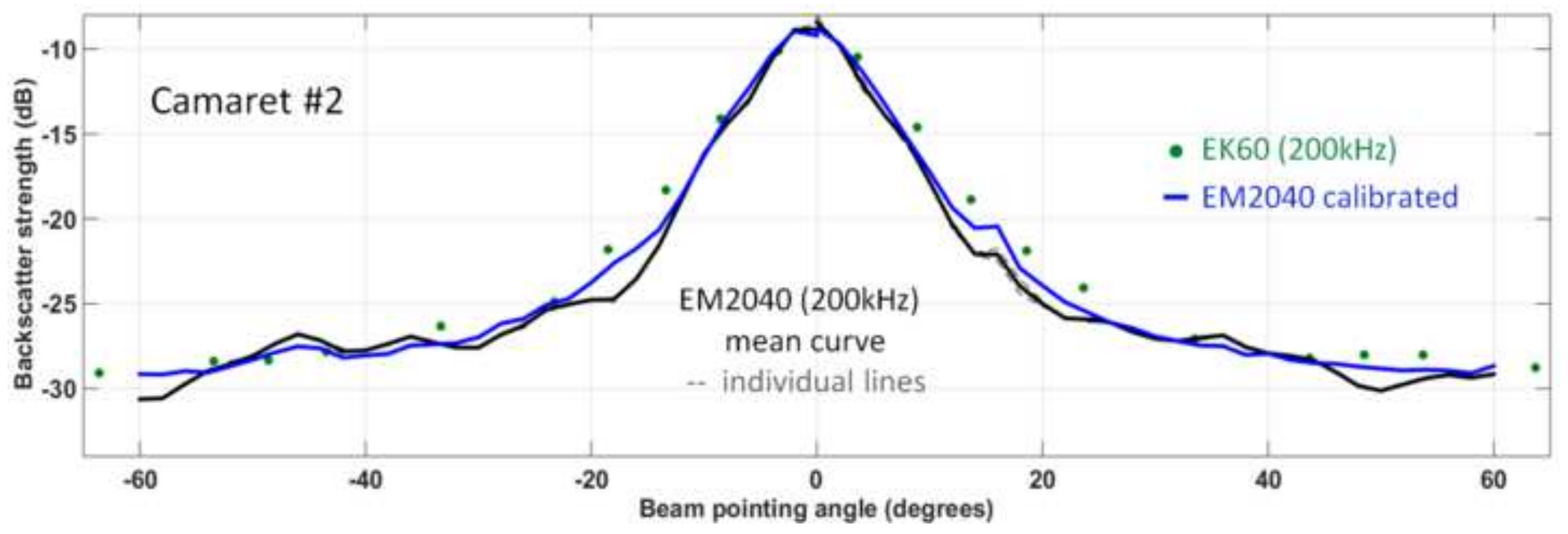




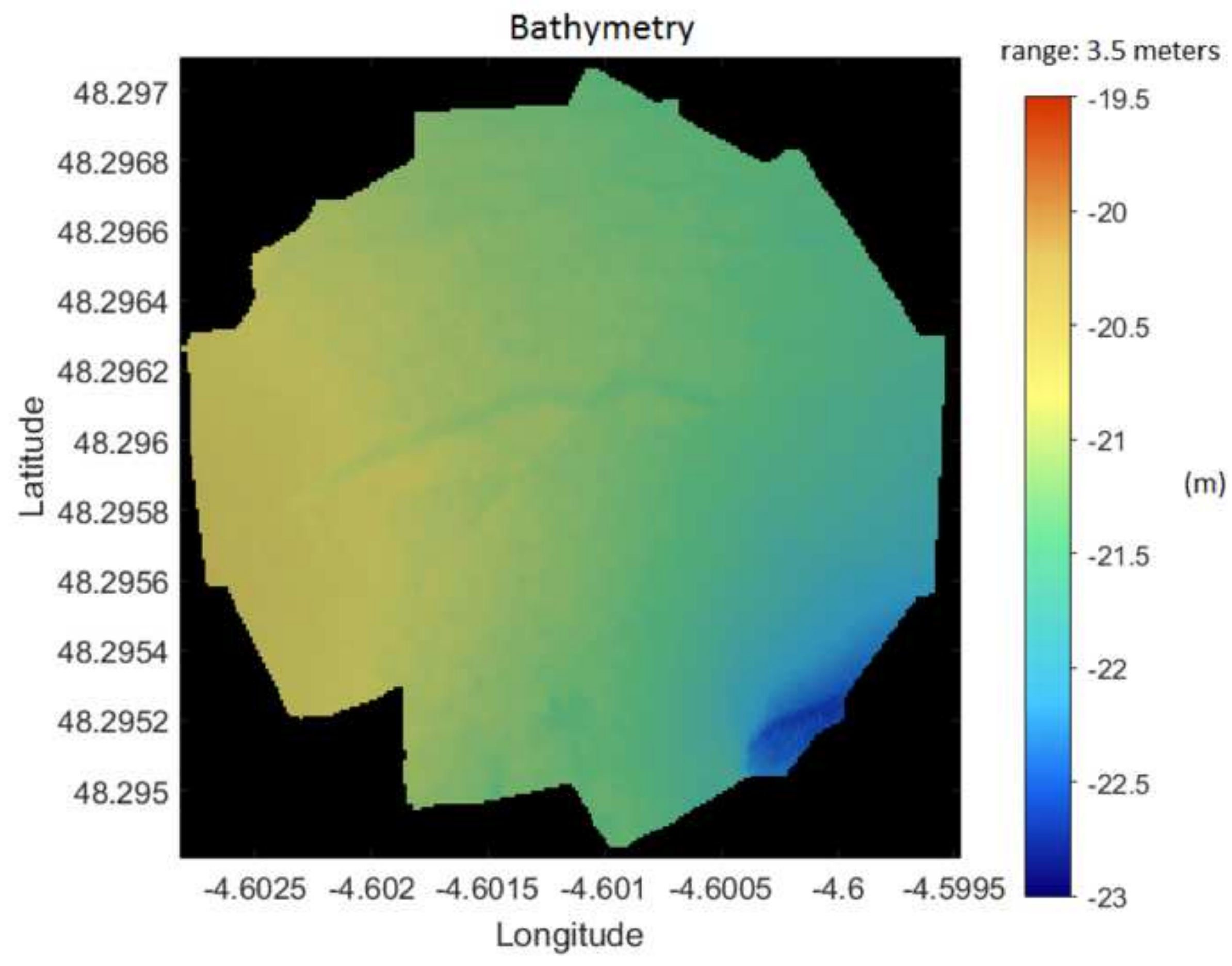




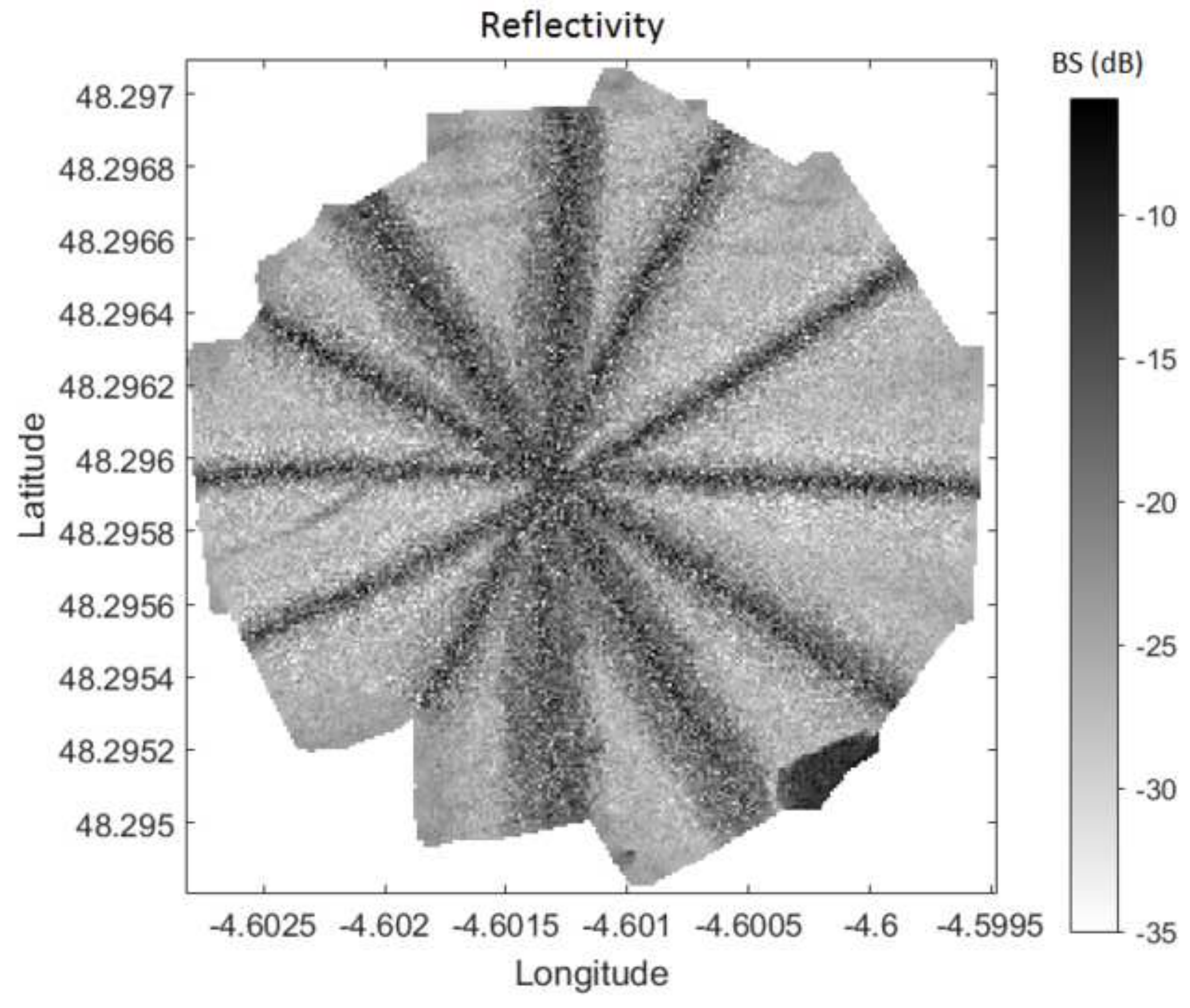




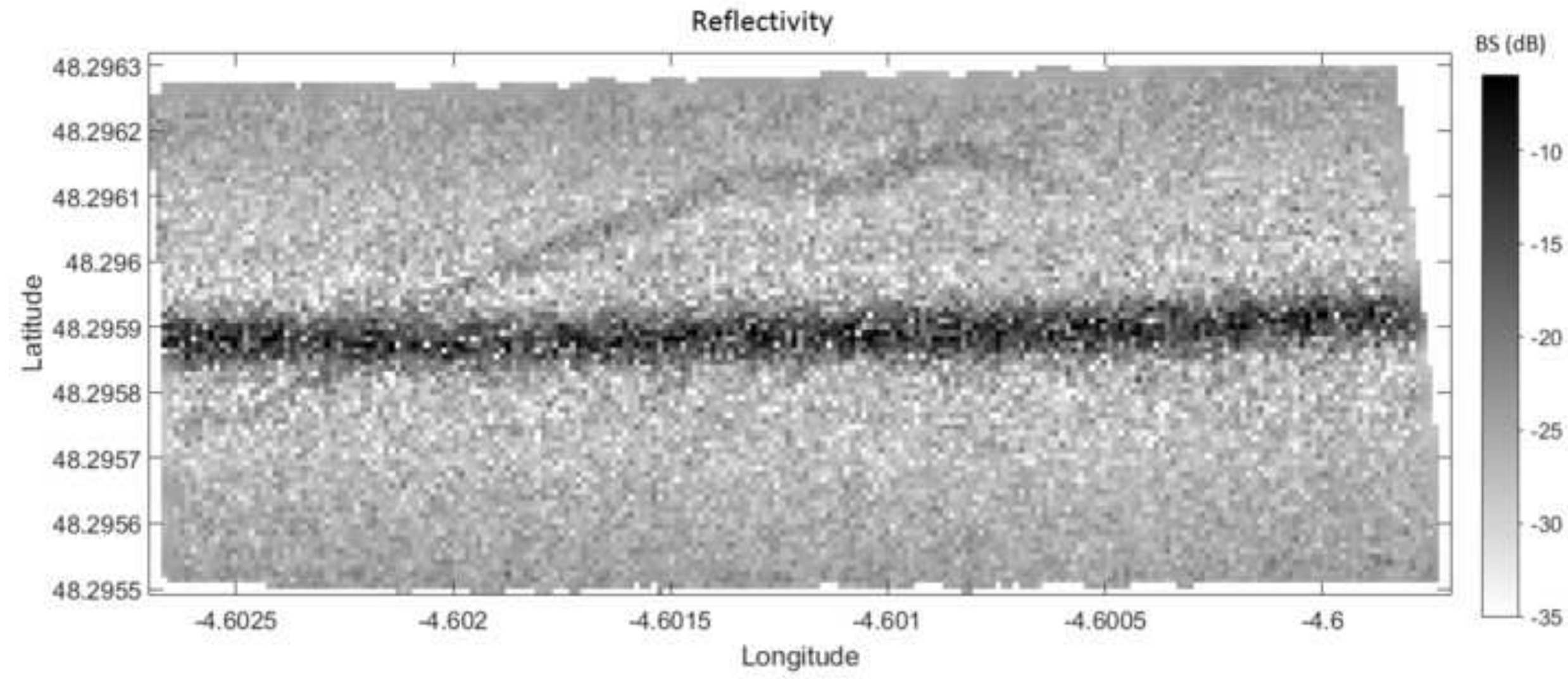




\section{Bathymetry}

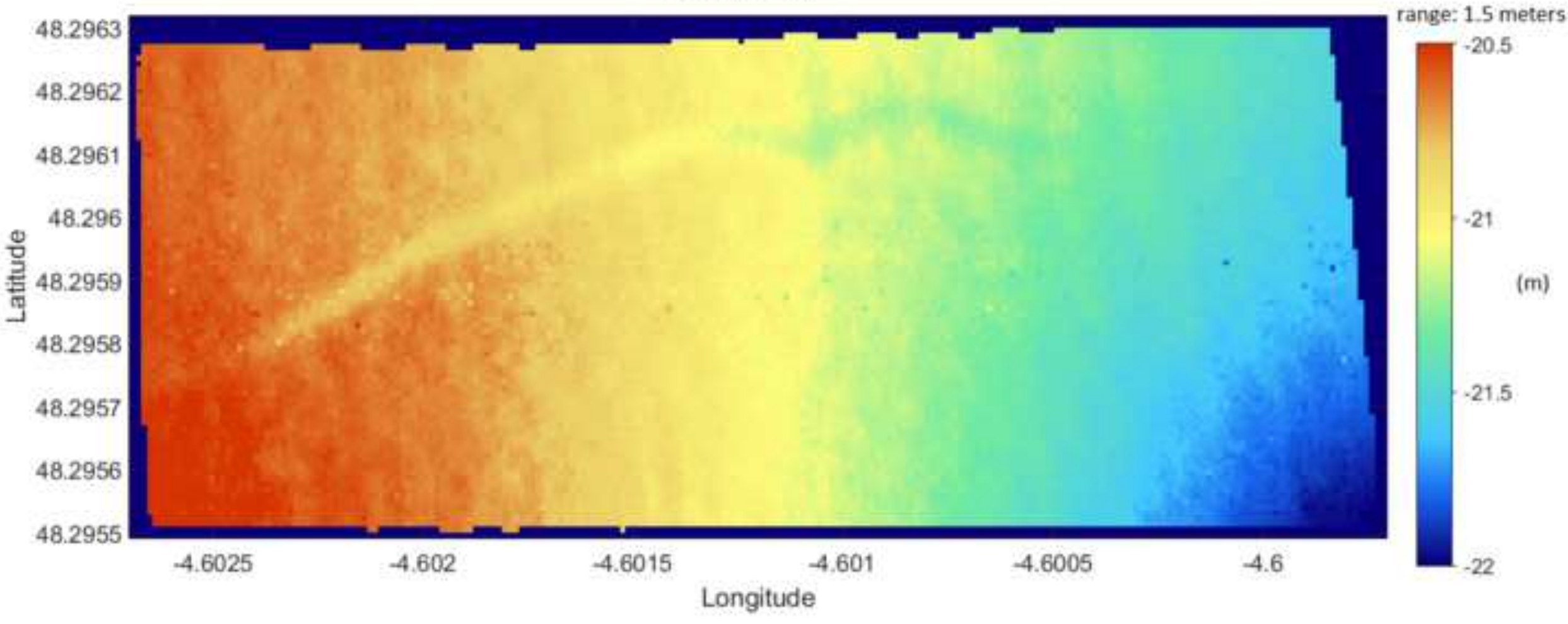


Click here to download Figure Figure 14.PNG $\underline{\underline{ }}$

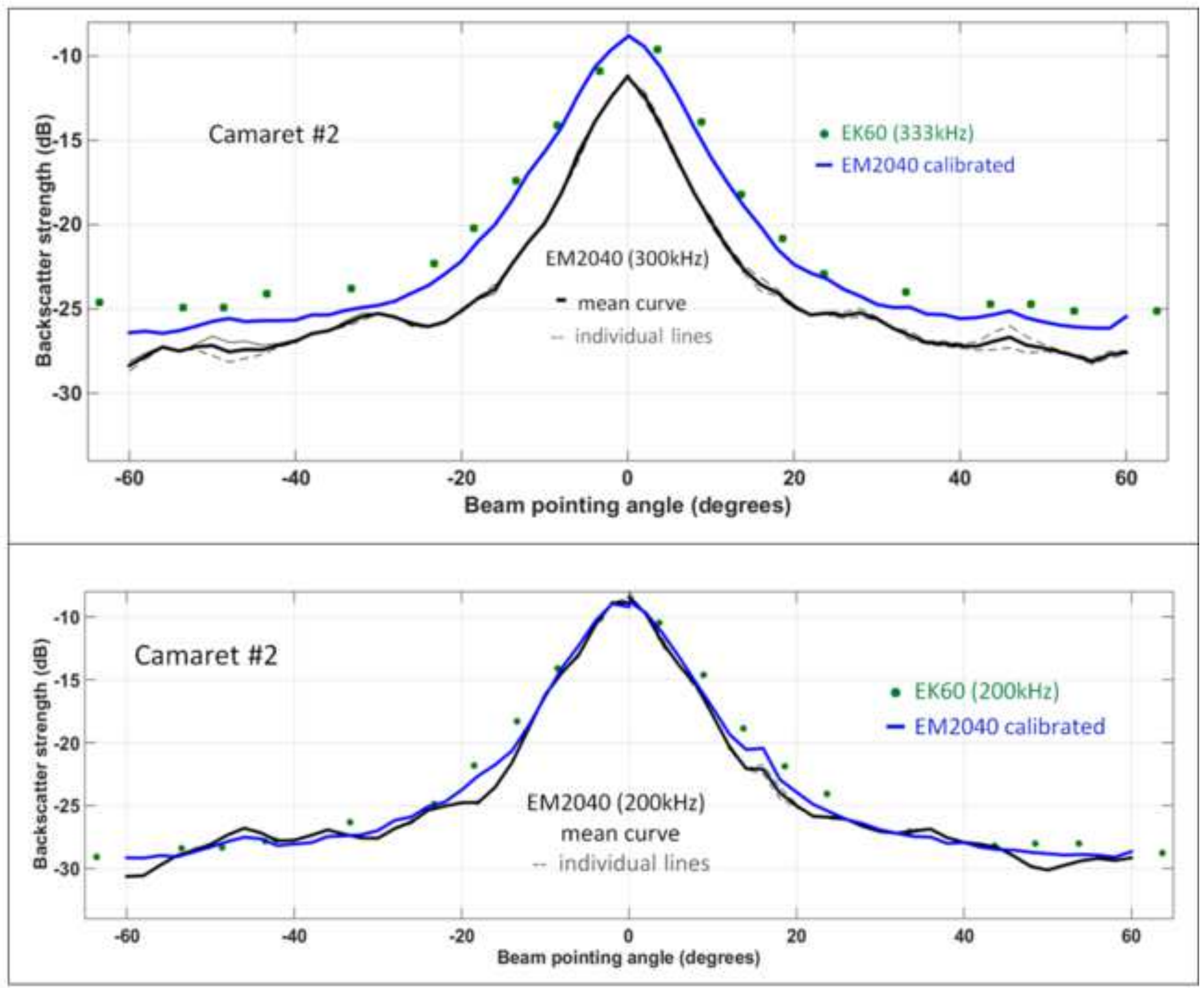




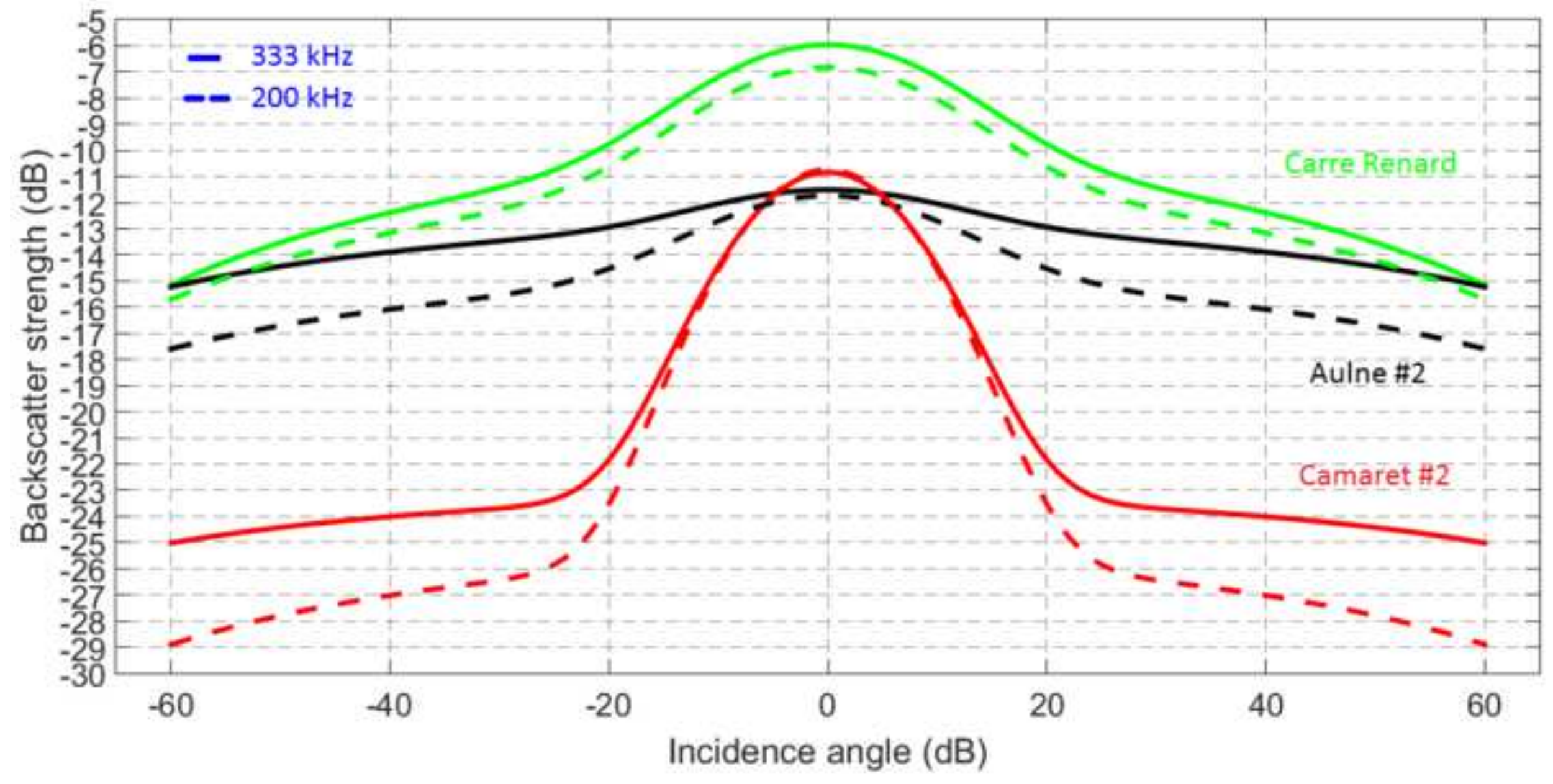




\begin{tabular}{|c|c|c|c|c|c|c|c|}
\hline $\begin{array}{c}\text { Frequency } \\
(\mathrm{kHz})\end{array}$ & $\begin{array}{c}\text { Pulse } \\
\text { length } \\
(\mu \mathrm{s})\end{array}$ & $\begin{array}{c}\text { Sphere } \\
\text { diameter } \\
(\mathrm{mm})\end{array}$ & $\begin{array}{c}G_{0} \\
(\mathrm{~dB})\end{array}$ & $\begin{array}{c}S_{a, \text { corr }} \\
(\mathrm{dB})\end{array}$ & $\begin{array}{c}\text { RMS } \\
(\mathrm{dB})\end{array}$ & $\begin{array}{c}\text { Athwartship } \\
\text { beamwidth }\left(^{\circ}\right)\end{array}$ & $\begin{array}{c}\text { Alongship } \\
\text { beamwidth }\left({ }^{\circ}\right)\end{array}$ \\
\hline 200 & 256 & 38.1 & 26.67 & -0.37 & 0.25 & 7.5 & 7.4 \\
\hline 333 & 256 & 22 & 27.07 & -0.38 & 0.44 & 7.4 & 7.5 \\
\hline
\end{tabular}




\begin{tabular}{|c|c|c|c|c|c|}
\hline $\begin{array}{c}\text { Frequency } \\
(\mathrm{kHz})\end{array}$ & Direction & $\begin{array}{c}\text { Measured one-way } \\
\text { 3dB beamwidth } \\
\text { Fresh water } \\
\mathrm{T}^{\circ}=20^{\circ} \mathrm{C} \\
\mathrm{c}=1482 \mathrm{~m} / \mathrm{s}\end{array}$ & $\begin{array}{c}\text { Two-way 3dB } \\
\text { beamwidth } \\
\text { Fresh water } \\
\mathrm{T}^{\circ}=20^{\circ} \mathrm{C} \\
\mathrm{c}=1482 \mathrm{~m} / \mathrm{s}\end{array}$ & $\begin{array}{c}\text { Effective two-way } \\
\text { beamwidth } \\
\text { Fresh water } \\
\mathrm{T}^{\circ}=20^{\circ} \mathrm{C} \\
\mathrm{c}=1482 \mathrm{~m} / \mathrm{s}\end{array}$ & $\begin{array}{c}\text { Effective two-way } \\
\text { beamwidth } \\
\text { Seawater } \\
\mathrm{T}^{\circ}=16.5^{\circ} \mathrm{C} \\
\mathrm{S}=34.5 \mathrm{PSU} \\
\mathrm{c}=1510 \mathrm{~m} / \mathrm{s}\end{array}$ \\
\hline 200 & along & $7.3^{\circ}$ & $5.2^{\circ}$ & $5.5^{\circ}$ & $5.6^{\circ}$ \\
\hline 200 & athwart & $7.4^{\circ}$ & $5.3^{\circ}$ & $5.6^{\circ}$ & $5.7^{\circ}$ \\
\hline 333 & along & $7.4^{\circ}$ & $5.3^{\circ}$ & $5.6^{\circ}$ & $5.7^{\circ}$ \\
\hline 333 & athwart & $7.3^{\circ}$ & $5.2^{\circ}$ & $5.5^{\circ}$ & $5.6^{\circ}$ \\
\hline
\end{tabular}




\begin{tabular}{|c|c|c|}
\hline Frequency $(\mathrm{kHz})$ & Carré Renard & Camaret \#2 \\
\hline 333 & 93.4 & 93.9 \\
\hline 300 & 86.8 & 87.2 \\
\hline 200 & 66.6 & 66.9 \\
\hline
\end{tabular}




\begin{tabular}{|l|c|c|c|c|c|}
\hline & \multicolumn{4}{|c|}{ GSAB parameters values } & \multirow{2}{*}{ RMSE (dB) } \\
\cline { 1 - 4 } $\begin{array}{l}\text { Frequency } \\
\mathrm{kHz})\end{array}$ & $10 \log A(\mathrm{~dB})$ & $B\left(^{\circ}\right)$ & $10 \log C(\mathrm{~dB})$ & $D$ & 0.24 \\
\hline 333 & -7.74 & 10.51 & -10.66 & 1.49 & 0.17 \\
\hline 200 & -8.58 & 10.55 & -11.59 & 1.37 & \\
\hline
\end{tabular}

